\title{
Some aspects of the NMR chemical shift/structure correlation in the structural characterization of polymers and biopolymers
}

\author{
Isao Ando \\ Studies on the NMR methodology for characterizing the structure of polymers and biopolymers based on the understanding of \\ the NMR chemical shift/structure correlation using solution-state and solid-state NMR experiments, the development of the \\ NMR chemical shift theory and their combination have been reviewed.
}

Polymer Journal (2012) 44, 734-747; doi:10.1038/pj.2012.95; published online 13 June 2012

Keywords: biopolymer; conformation; higher-order structure; hydrogen bond structure; NMR chemical shift; stereochemical structure

The first observation, according to the best of knowledge, of a highresolution 17.735- $\mathrm{MHz}{ }^{1} \mathrm{H}$ NMR spectrum of uncured Heva rubber in a $\mathrm{CS}_{2}$ solution was made in 1957 by Gutowsky et al., ${ }^{1}$ who observed the $\mathrm{CH}_{3}, \mathrm{CH}_{2}$ and $\mathrm{CH}$ signals to appear separately at different chemical shift positions. It was shown that the NMR chemical shift provides information on the chemical structure of polymers and can be used effectively in the chemical structure analysis and in the analysis of organic compounds. ${ }^{1,2}$ Furthermore, in 1960, Bovey and Tiers, ${ }^{3}$ Nishioka et al. ${ }^{4}$ and Johnsen and Tessmar ${ }^{5}$ independently reported a very important discovery for polymer science: the $\alpha-\mathrm{CH}_{3}$ signals in the ${ }^{1} \mathrm{H}$ NMR spectrum of poly(methyl methacrylate)s with different tacticities in chloroform solution appear at different chemical shift positions, in which the three splitting signals were assigned to the $r r, m r$ and $m m$ triads from upfield on the basis of sophisticated and reasonable experiments, where $m$ and $r$ are the meso and racemic dyads, respectively. Since that time, NMR spectroscopy has been well recognized to be the most powerful method available for characterizing the structures of polymers. This means that the chemical shift (chemical shielding), as one of the important NMR parameters, ${ }^{6}$ can be meaningfully used for the structural characterization of polymers.

With such a foundation, the sophisticated understanding and development of the NMR chemical shift/structure correlation for the structural characterization of polymers and biopolymers have been implemented as one of our research programs. In this review, it is shown by the author and his colleagues that understanding the NMR chemical shift/structure correlation provides a powerful methodology for the structural characterization of polymers and biopolymers based on the sophisticated development of solution-state and solid-state NMR experiments, the development of NMR chemical shift theory, and their combination. ${ }^{7,8}$

\section{THE CONCEPT OF THE NMR CHEMICAL SHIFT/STRUCTURE CORRELATION}

A polymer chain has an enormous number of chemical bonds. In the solution state, the NMR chemical shifts of polymers are generally the averaged values over all of the possible conformations because of the rapid interconversions by rotation around the chemical bonds. However, in solids, the chemical shifts are often characteristic of specific conformations because of strongly restricted rotation around the bonds. ${ }^{7,8}$ The NMR chemical shift is affected by a change in the electronic structure caused by the conformational change. Solid-state NMR chemical shifts, therefore, provide useful information about the electronic structure of a polymer chain and multiple polymer chains with a fixed structure. Furthermore, the complete chemical shift tensor components can often be determined because the chemical shift is, in principle, the second-rank tensor quantity. The complete chemical shift tensor components (the chemical shift anisotropy) of polymers and biopolymers provide information about the local symmetry of the electron cloud around the nucleus, and therefore, provide much more detailed knowledge about the conformation associated with electronic structure compared with the averaged chemical shift. To completely understand the NMR chemical shift/structure correlation of polymers and biopolymers, a sophisticated approach that combines solution-state and solid-state NMR experiments and NMR chemical shift theory has been implemented.

\section{A brief account of the NMR chemical shift}

The NMR chemical shifts of atoms in a polymer chain or multiple polymer chains, including biopolymers, depend on the electronic and molecular environments of the nuclei. The chemical shift for atom A 
$\left(\sigma_{\mathrm{A}}\right)$ can be precisely estimated as a sum of the following terms according to the theory of the chemical shift. ${ }^{9-13}$

$$
\sigma_{\mathrm{A}}=\sigma^{\mathrm{d}}+\sigma^{\mathrm{p}},
$$

where $\sigma^{\mathrm{d}}$ and $\sigma^{\mathrm{p}}$ are the diamagnetic term and the paramagnetic term, respectively. For nuclei with $2 p$ electrons, such as ${ }^{13} \mathrm{C},{ }^{15} \mathrm{~N},{ }^{17} \mathrm{O}$, and so on, considered here, the relative chemical shift is predominantly governed by the paramagnetic term. ${ }^{6-8}$ In the case of the ${ }^{1} \mathrm{H}$ chemical shift, another term, $\sigma^{\prime}$, is added to Equation (1), which can result from significant contributions to the chemical shift from the magnetic anisotropy effect, polar effect and ring current effect. Here, it is noted that the symbol $\sigma$ is used for the calculated chemical shift, the symbol $\delta$ is used for the experimental chemical shift, and that a positive sign for $\sigma$ signifies shielding and a positive sign for $\delta$ signifies deshielding.

Before describing details of the protocol for evaluation of the diamagnetic and paramagnetic contributions, it is noted that in an isotropic liquid or solution sample, the NMR chemical shift $\sigma$ is observed as a scalar quantity $\sigma_{\text {iso }}$, the isotropic chemical shift, due to the fast tumbling of molecules and polymers. However, in a solid or oriented molecules and polymers (such as a liquid crystalline or single crystalline samples), the chemical shift is not an isotropic parameter but a second-rank tensor. The components of the chemical shift tensor in these samples can be specified by $\sigma_{\mathrm{ij}}$, where $\mathrm{i}, \mathrm{j}=\mathrm{x}, \mathrm{y}$ or $\mathrm{z}$ in a reference frame fixed on the nucleus in a molecule and a polymer. Thus, the observation of the chemical shift tensor components, in principle, leads to more fruitful information about the structure compared with the observation of the $\sigma_{\text {iso. }}$ The magic angle spinning (MAS) experiment of a solid provides the $\sigma_{\text {iso }}$ as the isotropic average of the three principal components of the tensor as given by $\left(\sigma_{11}+\sigma_{22}+\right.$ $\left.\sigma_{33}\right) / 3$. Therefore, the line width of the NMR signal becomes very narrow.

Here, we are concerned with the protocol for evaluating the diamagnetic term $\sigma_{\alpha \beta}^{d}$ and the paramagnetic term $\sigma^{p}{ }_{\alpha \beta}$ for smallsize or medium-size model molecules of polymers and biopolymers. The wave function $\psi_{m}$ for an electron $m$ is expressed by

$$
\sigma_{\alpha \beta}^{\mathrm{d}}=\frac{\mu_{0}}{4 \pi} \frac{e^{2}}{m_{\mathrm{e}}^{2}} \sum_{\mathrm{m}}^{\mathrm{occ}}\left\langle\psi_{\mathrm{m}}\left|r^{-3}\left(r^{2} \delta_{\alpha \beta}-r_{\alpha} r_{\beta}\right)\right| \psi_{\mathrm{m}}\right\rangle
$$

and

$$
\begin{aligned}
\sigma_{\alpha \beta}^{\mathrm{p}}= & -\frac{\mu_{0}}{4 \pi} \frac{e^{2}}{m_{\mathrm{e}}^{2}} \sum_{\mathrm{m}}^{\text {occ }} \sum_{\mathrm{n}}^{\text {unocc }}\left({ }^{1} E_{\mathrm{m}}^{\mathrm{n}}-{ }^{1} E_{0}\right)^{-1} \\
& \times\left\{\left\langle\psi_{\mathrm{m}}\left|r^{-3} L_{\alpha}\right| \psi_{\mathrm{n}}\right\rangle\left\langle\psi_{\mathrm{n}}\left|L_{\beta}\right| \psi_{\mathrm{m}}\right\rangle+\left\langle\psi_{\mathrm{m}}\left|L_{\beta}\right| \psi_{\mathrm{n}}\right\rangle\left\langle\psi_{\mathrm{n}}\left|r^{-3} L_{\alpha}\right| \psi_{\mathrm{m}}\right\rangle\right\},
\end{aligned}
$$

using the sum-over-states (SOS) method, ${ }^{6}$ where the subscripts $\alpha$ and $\beta$ denote the Cartesian components $(\mathrm{x}, \mathrm{y}, \mathrm{z}), \mu_{0}$ is the permeability of free space, $m_{e}$ is the mass of the electron, and $L_{\alpha}$ is the orbital angular momentum operator. $\sum_{\mathrm{n}}^{\mathrm{occ}}$ and $\sum_{\mathrm{n}}^{\mathrm{unocc}}$ are the summation over the occupied and unoccupied molecular orbitals, respectively. The term $\left({ }^{1} E^{\mathrm{n}} \mathrm{m}-{ }^{1} E_{0}\right)$ is the electronic singlet-singlet excitation energy from the $m$ th to the $n$th orbital.

\section{Two approaches for NMR chemical shift calculations of polymers and biopolymers}

Two sophisticated approaches for calculating the NMR chemical shifts of polymers and biopolymers have been developed to understand the NMR chemical shift/structure correlation. The first approach (1) is for polymers and biopolymers in solution. A single polymer chain in solution can assume an enormous number of conformational configurations because of the rapid rotation around the chemical bonds. Thus, if the rotation around the bonds is very fast on the NMR timescale, the chemical shift for any specified atom $\mathrm{A}$ is observed as that averaged over the possible preferred conformations $\left(\left\langle\sigma_{\mathrm{A}}\right\rangle\right) .\left\langle\sigma_{\mathrm{A}}\right\rangle$ is given as $\left\langle\sigma_{\mathrm{A}}\right\rangle=\sum_{i=1}^{n} P_{i} \sigma_{i}$, where the numerical indices refer to the preferred conformations and $P_{\mathrm{i}}$ and $\sigma_{\mathrm{i}}$ are the probability of occurrence and the chemical shift of preferred conformation $i$, respectively. In approach (1), model molecules such as dimers, trimers, and so on. are used as the local structures of the polymer chains, and information about the conformational configuration of a polymer chain in solution has been obtained using a combination of chemical shift theory and polymer statistical mechanics. Such an approach has been carefully applied to characterize the stereochemical structures of some polymer systems in the solution state. ${ }^{7,8}$ For example, stereochemical structure (such as dyad, triad and tetrad tacticities) of poly(vinyl chloride) were successfully characterized through the observation of ${ }^{1} \mathrm{H}$ and ${ }^{13} \mathrm{C}$ NMR spectra in solution and calculating the chemical shift using approach (1). ${ }^{14-16}$ Furthermore, this approach led to establishment of using the chemical shift (contour) map for characterizing the second-order structure of polypeptides and using the hydrogen-bonded structure to analyze various types of amino acid residues of peptides and polypeptides. It should be recognized that the chemical shift calculations on model molecules are not always readily applicable to polymers in the crystalline state, because of the existence of long-range intrachain and interchain interactions. Electrons are constrained to a finite region of space in small molecules, whereas this is not necessarily the case for polymers, and thus another approach is required. The second approach (2) is to employ the tight-binding molecular orbital (TB MO) theory, which is well known in the field of solid-state physics, to describe the electronic structures of linear polymers with periodic structure within the framework of the linear combination of atomic orbitals approximation for the electronic eigenfunctions. ${ }^{17-19}$ Thus, the chemical shift theory has been combined with the TB MO theory, which can take into account long-range intrachain and interchain interactions in polymer systems. Such an approach is useful for obtaining an appropriate knowledge of the relationship between the electronic structure and the ${ }^{13} \mathrm{C}$ NMR chemical shifts of solid polymers. ${ }^{20-33}$

In the TB approximation, the wave function $\psi(\mathbf{k})$ for an electron at position $\mathbf{r}$, which belongs to the $n$th crystal orbital $(C O)$, is expressed with Bloch's theory as follows:

$$
\psi_{\mathrm{n}}(\mathbf{k})=N^{-1 / 2} \sum_{v} \sum_{\mathbf{R}} C_{v \mathrm{n}}(\mathbf{k}) \varphi_{v}(\mathbf{r}-\mathbf{R}) \exp (i \mathbf{k} \bullet \mathbf{R})
$$

where $v$ is the index of the atomic orbital, $N$ is the total number of unit cells, $\mathbf{k}$ is the wave vector expressed by $\mathbf{k}_{\mathrm{x}}+\mathbf{k}_{\mathrm{y}}+\mathbf{k}_{\mathrm{z}}$ and $\mathbf{R}$ is the lattice vector. The symbol $i$ denotes the imaginary number, and $C_{v v}(\mathbf{k})$ is the expansion coefficient for the atomic orbital $\phi_{v}(\mathbf{r}-\mathbf{R})$. Using the obtained expansion coefficients $C_{v v}(\mathbf{k})$, the ${ }^{13} \mathrm{C}$ NMR chemical shift can be expressed by $\sigma_{\mathrm{A}}(\mathbf{k})$ as a function of $\mathbf{k}^{22,23}$

The protocol for calculating the NMR chemical shift by the SOS method in the framework of the linear combination of atomic orbital approximation with the neglect of integrals involving more than two centers is derived. If the integrals involve the product of atomic orbitals on different atoms, the diamagnetic term $\sigma^{d}{ }_{\mathrm{A}}(\mathbf{k})$ can be 
expressed by

$$
\begin{aligned}
\sigma_{\alpha \beta}^{\mathrm{d}}(\mathbf{k})= & \frac{\mu_{0}}{4 \pi} \frac{e^{2}}{m_{\mathrm{e}}^{2}} \sum_{\mathrm{m}}^{\mathrm{occ}}\left\langle\psi_{\mathrm{m}}(\mathbf{k})\left|r^{-3}\left(r^{2} \delta_{\alpha \beta}-r_{\alpha} r_{\beta}\right)\right| \psi_{\mathrm{m}}(\mathbf{k})\right\rangle \\
= & \frac{\mu_{0}}{4 \pi} \frac{e^{2}}{m_{\mathrm{e}}^{2}} \frac{1}{N} \sum_{\mathrm{m}}^{\mathrm{occ}} \sum_{v v^{\prime}} C_{v \mathrm{~m}}^{*} C_{v^{\prime} \mathrm{m}}\left\langle\sum_{\mathbf{R}} \exp (i \mathbf{k} \cdot \mathbf{R}) v^{\mathbf{R}}\right| \\
& \times r^{-3}\left(r^{2} \delta_{\alpha \beta}-r_{\alpha} r_{\beta}\right)\left|\sum_{\mathbf{R}^{\prime}} \exp \left(i \mathbf{k} \cdot \mathbf{R}^{\prime}\right) v^{\prime} \mathbf{R}^{\prime}\right\rangle \\
= & \frac{\mu_{0}}{4 \pi} \frac{e^{2}}{m_{\mathrm{e}}^{2}} \sum_{\mathrm{m}}^{\mathrm{occ}} \sum_{v v^{\prime}} C_{v \mathrm{~m}}^{*} C_{v^{\prime} \mathrm{m}} \sum_{\mathbf{R}} \exp (i \mathbf{k} \cdot \mathbf{R}) \\
& \times\left\langle v^{\mathbf{R}}\left|r^{-3}\left(r^{2} \delta_{\alpha \beta}-r_{\alpha} r_{\beta}\right)\right| v^{\prime} \mathbf{R}\right\rangle,
\end{aligned}
$$

where the asterisk denotes the complex conjugate and $\left\langle v^{\mathrm{R}}\right|$ is the $v$ th atomic orbital in the Rth unit cell. The paramagnetic term $\sigma^{p}{ }_{\mathrm{A}}(\mathrm{k})$ can be expressed by

$$
\begin{aligned}
& \sigma_{\alpha \beta}^{\mathrm{p}}(\mathbf{k})=-\frac{\mu_{0}}{4 \pi} \frac{e^{2}}{m_{\mathrm{e}}^{2}} \sum_{\mathrm{m}}^{\text {occ }} \sum_{\mathrm{n}}^{\text {unocc }}\left({ }^{1} E_{\mathrm{m}}-{ }^{1} E_{0}\right)^{-1} \\
& \times\left\{\left\langle\psi_{\mathrm{m}}(\mathbf{k})\left|r^{-3} L_{\alpha}\right| \psi_{\mathrm{n}}(\mathbf{k})\right\rangle\left\langle\psi_{\mathrm{n}}(\mathbf{k})\left|L_{\beta}\right| \psi_{\mathrm{m}}(\mathbf{k})\right\rangle\right. \\
&\left.+\left\langle\psi_{\mathrm{m}}(\mathbf{k})\left|L_{\beta}\right| \psi_{\mathrm{n}}(\mathbf{k})\right\rangle\left\langle\psi_{\mathrm{n}}(\mathbf{k})\left|r^{-3} L_{\alpha}\right| \psi_{\mathrm{m}}(\mathbf{k})\right\rangle\right\} \\
&=-\frac{\mu_{0}}{4 \pi} \frac{e^{2}}{m_{e}^{2}} \sum_{\mathrm{m}}^{\mathrm{occ}} \sum_{\mathrm{n}}^{\mathrm{unocc}}\left({ }^{1} E_{\mathrm{m}}^{\mathrm{n}}-{ }^{1} E_{0}\right)^{-1} \times\left[\frac{1}{N} \sum_{v v^{\prime}} C_{v \mathrm{~m}}^{*} C_{v^{\prime} \mathrm{n}}\right. \\
&\left\langle\sum_{\mathbf{R}} \exp (i \mathbf{k} \cdot \mathbf{R}) v^{\mathbf{R}}\left|r^{-3} L_{\alpha}\right| \sum_{\mathbf{R}^{\prime}} \exp \left(i \mathbf{k} \cdot \mathbf{R}^{\prime}\right) v^{\prime} \mathbf{R}^{\prime}\right\rangle \\
& \times \frac{1}{N} \sum_{v v^{\prime}} C_{v^{\prime} \mathrm{n}}^{*} C_{v \mathrm{~m}}\left\langle\sum_{\mathbf{R}^{\prime}} \exp \left(i \mathbf{k} \cdot \mathbf{R}^{\prime}\right) v^{\prime} \mathbf{R}^{\prime}\left|L_{\beta}\right| \sum_{\mathbf{R}^{\prime}} \exp (i \mathbf{k} \cdot \mathbf{R}) v^{\mathbf{R}}\right\rangle \\
&+\frac{1}{N} \sum_{v v^{\prime}} C_{v \mathrm{~m}}^{*} C_{v^{\prime} \mathrm{n}}\left\langle\sum_{\mathbf{R}} \exp (i \mathbf{k} \cdot \mathbf{R}) v^{\mathbf{R}}\left|L_{\beta}\right| \sum_{\mathbf{R}^{\prime}} \exp \left(i \mathbf{k} \cdot \mathbf{R}^{\prime}\right) v^{\prime} \mathbf{R}^{\prime}\right\rangle \\
& \times \frac{1}{N} \sum_{v v^{\prime}} C_{v^{\prime} \mathrm{n}}^{*} C_{v \mathrm{~m}}\left\langle\sum_{\mathbf{R}^{\prime}} \exp \left(i \mathbf{k} \cdot \mathbf{R}^{\prime}\right) v^{\prime} \mathbf{R}^{\prime}\left|r^{-3} L_{\alpha}\right| \sum_{\mathbf{R}^{\prime}} \exp (i \mathbf{k} \cdot \mathbf{R}) v^{\mathbf{R}}\right\rangle,
\end{aligned}
$$

where the angular momentum integral has a non-zero value only between orbitals with the same angular momentum quantum number because of the orbital orthogonality. The detailed derivation of these equations for evaluating $\sigma_{\mathrm{A}}(\mathbf{k})=\sigma^{\mathrm{d}}{ }_{\mathrm{A}}(\mathbf{k})+\sigma^{\mathrm{P}}{ }_{\mathrm{A}}(\mathbf{k})$ has been previously reported. ${ }^{22,23}$

To compare the calculated chemical shift $\sigma_{\mathrm{A}}$ with the experimental chemical shift, one needs to integrate over the first Brillouin zone as expressed by

$$
\sigma_{\mathrm{A}}=\frac{\Omega}{8 \pi^{3}} \int_{\mathrm{BZ}}\left\{\sigma_{\mathrm{A}}^{\mathrm{d}}(\mathbf{k})+\sigma_{\mathrm{A}}^{\mathrm{p}}(\mathbf{k})\right\} d \mathbf{k},
$$

where $\Omega$ is the volume of the primitive cell. Thus, by such a treatment of $\sigma_{A}(\mathbf{k})$ over $\mathbf{k}$, the NMR chemical shift $\sigma_{\mathrm{A}}$ can be compared with the experimental chemical shift.

Single polymer chain and multi polymer chains approaches Conformation-dependent ${ }^{13} \mathrm{C}$ chemical shifts of various types have been systematically studied for a single polymer chain such as polyethylene, cis- and trans-polyacetylenes, polyoxymethylene, polypyrrole, polyoxyethylene and polypeptides such as polyglycine, poly(L-alanine), $\operatorname{poly}\left(\beta\right.$-benzyl L-aspartate) and poly(L-proline). ${ }^{20-31} \mathrm{It}$ has been shown that the concept of the ${ }^{13} \mathrm{C}$ chemical shift/structure correlation that has been clarified by the experimental and calculated results is a very useful means for the structural characterization of polymer and biopolymer systems. For example, the experimental ${ }^{13} \mathrm{C}$ chemical shifts for the $\alpha$-helix, $\omega$-helix and $\beta$-sheet forms of polypeptides in the solid state have been verified to be conformationdependent. $^{24,25}$

Next, we are concerned with the crystallographic effects on the ${ }^{13} \mathrm{C}$ chemical shifts of polyethylene, which is in the orthorhombic form when obtained under ordinary state conditions and in the monoclinic form when obtained under special state conditions. It is well known that the orthorhombic form is more stable than the monoclinic form. In the former, the all-trans zigzag planes are perpendicular to each other but are parallel to each other in the latter. The ${ }^{13} \mathrm{C}$ chemical shift calculations of polyethylene have been carried out with the $\mathrm{TB}$ $\mathrm{CNDO} / 2$ SOS method by using three infinite polyethylene chains in the orthorhombic and monoclinic forms by changing the interchain distance $R .^{26}$ The dependence of the calculated ${ }^{13} \mathrm{C}$ chemical shift $(\sigma)$ of the $\mathrm{CH}_{2}$ carbons of the central polyethylene chain in orthorhombic and monoclinic polyethylenes on the interchain distance $R$ has been employed. The calculations have been carried out by varying $R$ from 3 to $5 \AA$. For the orthorhombic form, the ${ }^{13} \mathrm{C}$ chemical shift $\left(\sigma_{\text {orth }}\right)$ moves upfield as $R$ increases from 3 to $4.5 \AA$ and downfield as $R$ increases beyond $4.5 \AA$. For the monoclinic form, the overall tendency of the $R$ dependence on the ${ }^{13} \mathrm{C}$ chemical shift $\left(\sigma_{\text {mono }}\right)$ is close to that for the orthorhombic form except that the value of $R$ at which the downfield shift occurs is approximately $4.0 \AA$. It was determined from $\mathrm{X}$-ray diffraction that the $R$ value for the orthorhombic form is $4.0 \AA$ and that for the monoclinic form is $4.08 \AA$. At these $R$ values, the ${ }^{13} \mathrm{C}$ chemical shift values $(\sigma)$ for the orthorhombic and monoclinic forms are -58.6 and -56.7 p.p.m., respectively, where the negative sign denotes deshielding. Therefore, as the experimental chemical shift $(\delta)$ is deshielding, the relative difference in the calculated chemical shift $(\sigma)$ should be compared with the observed $\delta$. This means that the expective ${ }^{13} \mathrm{C}$ chemical shift of orthorhombic polyethylene appears at a higher field by 1.9 p.p.m. than that of monoclinic polyethylene. As the experimental ${ }^{13} \mathrm{C}$ chemical shift of orthorhombic polyethylene appears at a higher field by 1.2 p.p.m. than that of monoclinic polyethylene, the calculations reasonably explain the experimental results. From this result, it can be seen that such a chemical shift displacement is caused by a local change in the intermolecular interactions when going from the orthorhombic form to the monoclinic form. Furthermore, the ${ }^{13} \mathrm{C}$ chemical shifts and the electronic structure for seven polyethylene chains with the orthorhombic and monoclinic forms have been studied by using the TB INDO/S SOS method. ${ }^{30}$ The ${ }^{13} \mathrm{C}$ chemical shift calculations reasonably explain the experimental results. From these results, the angle $\varphi$ between the $b$ axis in the orthorhombic lattice system and the all-trans zigzag plane was determined to be $25^{\circ}-42^{\circ}$. The total energy for the unit cell was determined to be $-95.1997 \mathrm{eV}$ for orthorhombic polyethylene and $-95.1989 \mathrm{eV}$ for monoclinic polyethylene. These calculated results agree with the experimental results that the orthorhombic form is more stable than the monoclinic form.

\section{Three-dimensional (3D) polymer crystals}

The protocol for calculating the NMR chemical shift of a 3D polymer crystal by a combination of $a b$ initio TB MO theory and the SOS method of the chemical shift theory has been derived. ${ }^{32}$ This has the potential for understanding and developing NMR chemical shift/ 
structure correlations for the structural characterization of $3 \mathrm{D}$ polymer crystals, organic crystals, and so on.

This protocol has been applied to the calculation of the ${ }^{13} \mathrm{C} N M R$ chemical shifts of $3 \mathrm{D}$ polyethylene crystals with the orthorhombic and the monoclinic forms by using the STO-3G minimal basis set. It is noted that the ${ }^{13} \mathrm{C}$ chemical shift position of polyethylene with the orthorhombic form appears at a higher field by approximately 1 p.p.m. than that of the monoclinic form. It is very significant to clarify whether or not such a chemical shift difference comes from the difference in the electronic structure between the crystallographic forms. By using three and seven infinite polyethylene chains as the orthorhombic and monoclinic models in a semi-empirical MO framework, it was approximated that the chemical shift difference comes from the packing effect arising from different crystallographic forms. For this analysis, the effects of the interchain and intrachain interactions on the ${ }^{13} \mathrm{C}$ NMR chemical shift and the band structure have been sophisticatedly evaluated by changing the $a, b$ and $c$ axis lattice constants in a polymer crystal.

Furthermore, this ab initio $\mathrm{MO}$ approach for a polymer crystal has been applied to elucidate the effect of the intrachain and interchain interactions on the ${ }^{13} \mathrm{C}$ chemical shifts of cis- and trans-polyacetylenes in the solid state. ${ }^{33}$ Before expanding the approach to a $3 \mathrm{D}$ polyacetylene crystal, it is useful to examine a single polyacetylene chain with the trans- and cis-forms to clarify the intermolecular interaction effect of the electronic structure on the NMR chemical shift behavior. The total energy per monomer unit and the NMR chemical shielding for a single polyacetylene chain with the cis- and trans-forms are obtained by using the $a b$ initio TB MO method within the framework of the STO-3G minimal basis set. It was shown that the total energy per monomer unit for trans-polyacetylene is lower than that for cis-polyacetylene by 0.0069 a.u. This means that the trans-form is more stable than the cis-form. The trends in the calculated results qualitatively explain the experimental finding that undoped trans-polyacetylene is thermally more stable than cispolyacetylene. Next, we are concerned with the calculated chemical shieldings for cis-and trans-polyacetylenes. The experimental ${ }^{13} \mathrm{C}$ chemical shift of the cis-form appears at a higher field by 10 p.p.m. than that of the trans-form. However, the calculation shows that the ${ }^{13} \mathrm{C}$ chemical shift of the cis-form is at slightly a higher field by 0.1 p.p.m. than that of the trans-form. When compared with the experimental results, the chemical shift difference between the cis- and trans-forms is very small. It has been shown that the single polymer chain model is insufficient to reasonably explain the experimental results and that the interchain interactions must be taken into account in a $3 \mathrm{D}$ polymer crystal.

The electronic structures and ${ }^{13} \mathrm{C}$ chemical shifts of $3 \mathrm{D}$ infinite cisand trans-polyacetylene crystals with the orthorhombic crystallographic form have been calculated by using the $a b$ initio TB MO method within the framework of the STO-3G minimal basis set. The total energies per monomer unit and the chemical shifts have been obtained. The total energy per monomer unit for the trans-form is lower than that of the cis-form by 0.0024 a.u. The trans-form is reasonably predicted to be more stable than the cis-form. The ${ }^{13} \mathrm{C}$ chemical shift of the cis-form in polyacetylene crystal appears at a higher field by 1.0 p.p.m. than that of the trans-form; this was calculated by using the experimental lattice parameters. The calculated results more closely approach the experimental values compared with the results from the single polymer chain model. This shows that the intermolecular interactions have an important role for the ${ }^{13} \mathrm{C}$ chemical shift behavior. When the lattice parameter $a$ is reduced to $5 \AA$ (signifying an increase in the intermolecular interactions), the ${ }^{13} \mathrm{C}$ chemical shift difference between the cis- and trans-forms becomes 4.5 p.p.m. Then, when the length of the lattice parameter $a$ is approximately $4.7 \AA$, the calculated ${ }^{13} \mathrm{C}$ chemical shift difference becomes 10 p.p.m. and then agrees with the experimental value. This result indicates that the ${ }^{13} \mathrm{C}$ chemical shift is a very sensitive parameter for investigating the intermolecular interactions in a polymer crystal. From the above results, it has been shown that structural elucidation of polymer crystals and organic crystals can be carried out by a combination of the $\mathrm{NMR}{ }^{13} \mathrm{C}$ chemical shift experiments and the $3 \mathrm{D}$ polymer crystal $\mathrm{MO} /$ chemical shift method developed by us.

\section{CONFORMATION-DEPENDENT NMR CHEMICAL SHIFTS OF PEPTIDES AND POLYPEPTIDES IN THE SOLID STATE}

The primary structures of synthetic polypeptides consisted of repeating sequences of certain amino acid residues are not as complicated as those in proteins. Synthetic polypeptides are very important polymers in polymer science and protein science because the characteristic properties related to the structure lead to the expansion of research fields in polymer science and are very different from conventional synthetic polymers. Furthermore, synthetic polypeptides are sometimes used as model biomolecules for proteins because they form the $\alpha$-helix, $\beta$-sheet, $\omega$-helix, and so on. under appropriate conditions. From such situations, synthetic polypeptides can be considered to be 'interdisciplinary' macromolecules that are very important for research works in both polymer science and protein science.

As is well known, most of the peptides, polypeptides and proteins considered here consist of repeating sequences of peptide bonds with 20 different types of substituents at the $\mathrm{C}_{\alpha}$ carbon. The limited conformations such as the $\alpha$-helix, $\omega$-helix, $\beta$-sheet, and so on. are taken into consideration by using a set of the possible dihedral angles $(\Phi, \Psi)$ around the $\mathrm{N}-\mathrm{C}_{\alpha}$ and $\mathrm{C}_{\alpha}-\mathrm{C}(=\mathrm{O})$ bonds. In the solution state, the NMR chemical shift of these biomolecules with the possible rotation around the bonds sometimes becomes the averaged value for the possible rotations around the peptide bonds in the NMR timescale. In the solid state, however, the chemical shift is characteristic of specific conformations because the internal rotation around the peptide bonds is fixed. This shows that the NMR chemical shift can be used to elucidate the conformation of polypeptides and proteins in the solid state. It has been experimentally and theoretically shown that the NMR chemical shift of polypeptides and proteins is a very important NMR parameter for determining the main-chain conformation, and some studies on the structural characterization of polypeptides and proteins by using such a methodology will be discussed below.

\section{Conformation-dependent ${ }^{13} \mathrm{C}$ chemical shifts}

For example, it has been shown that the ${ }^{13} \mathrm{C}$ chemical shifts of the $\mathrm{C}_{\alpha}$, $\mathrm{C}_{\beta}$ and amide $\mathrm{C}=\mathrm{O}$ carbons of poly(L-alanine) ((Ala) $)_{\mathrm{n}}$ ) are closely related to its particular conformations. ${ }^{34}$ The observed ${ }^{13} \mathrm{C}$ CP-MAS (cross polarization-MAS) NMR spectra of solid poly(L-alanine) show the $\mathrm{C}_{\alpha}, \mathrm{C}_{\beta}$ and amide $\mathrm{C}=\mathrm{O}$ carbon signals to be well resolved between the $\alpha$-helix and $\beta$-sheet forms. It has also been shown from the plots of the observed ${ }^{13} \mathrm{C}$ chemical shifts against the numberaverage degree of polymerization that the ${ }^{13} \mathrm{C}$ chemical shifts of $(\mathrm{Ala})_{\mathrm{n}}$ with the $\alpha$-helix form $(n>16)$ and the $\beta$-sheet form $(n<16)$ are unchanged for the peptides of various molecular weight within the experimental error, and thus can serve to characterize the $\alpha$-helix form and the $\beta$-sheet form. The chemical shifts of the $\mathrm{C}_{\alpha}$ and carbonyl carbons of the $\alpha$-helix form are significantly displaced downfield by 4.2 and 4.6 p.p.m., respectively, relative to those of the 
$\beta$-sheet form, whereas the chemical shift of the $\mathrm{C}_{\beta}$ carbon of the $\alpha$-helix form is displaced upfield by approximately 5 p.p.m. with respect to that of the $\beta$-sheet form. For this reason, the ${ }^{13} \mathrm{C}$ chemical shift values can be used to describe the local conformation. In addition, the ${ }^{13} \mathrm{C}$ chemical shift of randomly coiled $(\mathrm{Ala})_{\mathrm{n}}$ in trifluoroacetic acid solution has a value between those of the $\alpha$-helix form and $\beta$-sheet form.

The existence of such characteristic displacements of ${ }^{13} \mathrm{C}$ chemical shifts is not limited to the Ala residue. Table 1 summarizes the ${ }^{13} \mathrm{C}$ chemical shift values of various amino acid residues in the $\alpha$-helix and $\beta$-sheet forms relative to tetramethylsilane. ${ }^{35-38,40}$ Here, it is seen that the $\mathrm{C}_{\alpha}$ and $\mathrm{C}=\mathrm{O}$ peaks of the $\alpha$-helix form are all displaced downfield with respect to those of the $\beta$-sheet form, consistent with the experimental data of $(\mathrm{Ala})_{\mathrm{n}}$. Furthermore, the ${ }^{13} \mathrm{C}$ chemical shift values are significant for the various conformations of $\operatorname{poly}(\beta$-benzyl L-aspartate) (PBLA; $\left.(\operatorname{Asp}(\mathrm{OBzl}))_{\mathrm{n}}\right)$, such as the right-handed $\alpha\left(\alpha_{\mathrm{R}}\right)$ helix, left-handed $\alpha\left(\alpha_{\mathrm{L}}\right)$-helix, left-handed $\omega\left(\omega_{\mathrm{L}}\right)$-helix and $\beta$-sheet forms, which are achieved by appropriate treatments to the polypeptide chain. ${ }^{41}$ It is shown that the absolute ${ }^{13} \mathrm{C}$ chemical shifts of the $\mathrm{C}_{\alpha}$ and $\mathrm{C}_{\beta}$ carbons are affected by the chemical structure of the individual amino-acid residues and can be used effectively for conformational studies of the particular amino acid residues in polypeptides and proteins. However, the $\mathrm{C}=\mathrm{O}$ chemical shifts do not seem to be affected by the residue structure and thus can be used to determine the main-chain conformation. This method has been applied for the structural characterization of collagen proteins, ${ }^{42}$ wool keratin ${ }^{43,44}$ silk protein,${ }^{45}$ polypeptide liquid crystals, ${ }^{46,47}$ polypeptide gels ${ }^{48,49}$ and polypeptide blends. ${ }^{50,51}$ Other peptide systems analyzed by this method are reviewed in Saito et al. ${ }^{40,52}$

It is known that changes in the helix sense of polypeptides in the solid state often occur because of changes in external conditions, such as temperature and so on, and changes in the side-chain conformation also often induce changes in the helix sense of the main-chain or the other conformations. The change in helix sense subsequently changes the nature of the polypeptides. PBLA samples with various secondary structures can be obtained by heat treatment with different temperatures. ${ }^{41}$ This has been demonstrated by real-time temperature-variable ${ }^{13} \mathrm{C}$ CP-MAS NMR measurements. ${ }^{53}$ It was seen that PBLA takes the $\alpha_{\mathrm{R}}$-helix form at room temperature, and by elevating the temperature, the $\alpha_{\mathrm{R}}$-helix form is gradually changed to the $\omega_{\mathrm{L}}$-helix form and, at the same time, slightly to the $\beta$-sheet form. Then, at approximately $150{ }^{\circ} \mathrm{C}$, the $\alpha_{\mathrm{R}}$-helix form completely disappears and the $\omega_{\mathrm{L}}$-helix form becomes the major component, and at $173^{\circ} \mathrm{C}$, the $\omega_{\mathrm{L}}$-helix form is completely changed to the $\beta$-sheet form. Furthermore, real-time temperature-variable ${ }^{13} \mathrm{C}$ CP-MAS NMR measurements have $\operatorname{shown}^{54,55}$ that poly $(\gamma-n$-alkyl L-glutamate) with long $n$-octadecyl side chains forms the thermotropic liquid-crystalline state by the melting of the side chains at approximately $50{ }^{\circ} \mathrm{C}$ because the main chain only takes the rigid $\alpha$-helix form at temperatures higher than approximately $50{ }^{\circ} \mathrm{C}$, but $\operatorname{poly}(\beta$ - $n$-alkyl L-aspartate $)$ with long $n$-octadecyl side chains does not form the thermotropic liquid-crystalline state by the melting of the side chains at approximately $50^{\circ} \mathrm{C}$ because the mainchain changes from the $\alpha_{\mathrm{R}}$-helix form to the $\alpha_{\mathrm{L}}$-helix form at temperatures higher than approximately $50{ }^{\circ} \mathrm{C}$ and thus is not rigid. Such a transitional change in the helix sense from the right-handed helix form to the left-handed helix form induces changes in the nature of the polypeptides.

Conformation-dependent ${ }^{15} \mathrm{~N}$ chemical shifts

Conformation-dependent ${ }^{15} \mathrm{~N}$ chemical shifts of solid homopolypeptides, such as ${ }^{15} \mathrm{~N}$-labeled poly(L-alanine) with the $\alpha$-helix and $\beta$-sheet forms, poly(L-leucine) with the $\alpha$-helix and $\beta$-sheet forms, and so on, ${ }^{56,57}$ have been studied by solid state ${ }^{15} \mathrm{~N}$ CP-MAS NMR as for the conformation-dependent ${ }^{13} \mathrm{C}$ chemical shift case. It has been confirmed from these experimental results that the isotropic ${ }^{15} \mathrm{~N}$ chemical shifts caused by the peptide backbone of homopolypeptides in the solid state exhibit a significant conformation-dependent change from observations and theoretical calculations. It has been shown that the $\delta_{\text {iso }}$ s for the $\alpha$-helix form of the homopolypeptides are 97.0-99.2 p.p.m. relative to Gly- ${ }^{15} \mathrm{~N}$ and those for the $\beta$-sheet form are $99.0-107.0$ p.p.m., and thus the $\alpha$-helix form appears upfield by approximately $1.2-10.0$ p.p.m. with respect to the $\beta$-sheet form. The conformation-dependent ${ }^{15} \mathrm{~N}$ chemical shift obviously depends on the structure of the individual amino-acid residues. Some ${ }^{15} \mathrm{~N}$ chemical shift differences are rather small, but they should be within acceptable limits for homopolypeptides. The variations of the $\delta_{\text {iso }}$ values for various types of homopolypeptides are approximately 2.5 p.p.m. in the $\alpha$-helix form and approximately 7.5 p.p.m. in the $\beta$-sheet form. Additionally, the $\delta_{\text {iso }}$ values of the $\beta$-sheet form of the L-Leu, L-Val and L-Ile residues with alkyl side chains appear downfield with respect to that of the L-Ala residue. In contrast, the $\delta_{\text {iso }}$ values for the $\beta$-sheet form of L-Asp(OBzl), L-Glu(OBzl $)(\gamma$-benzyl L-glutamate) and L-Glu $(\mathrm{OMe})(\gamma$-methyl L-glutamate) residues with a side-chain ester appear upfield with respect to the $\delta_{\text {iso }}$ value of the L-Ala residue. This means that the ${ }^{15} \mathrm{~N}$ chemical shift difference between the $\alpha$-helix and $\beta$-sheet forms depends on the side-chain structure of the individual amino-acid residues. Another result is that the $\delta_{\text {iso }}$ values of the righthanded $\alpha\left(\alpha_{\mathrm{R}}\right)$-helix and left-handed $\alpha\left(\alpha_{\mathrm{L}}\right)$-helix forms of PBLA in the solid state are 99.2 and 97.0 p.p.m., respectively, and thus the former appears at a lower field by 2.2 p.p.m. than the latter. This means that the ${ }^{15} \mathrm{~N} \delta_{\text {iso }}$ results provide information about the helix sense as for the ${ }^{13} \mathrm{C} \delta_{\text {iso }}$ results.

Isotropic ${ }^{15} \mathrm{~N}$ chemical shifts and tensor components have been determined by solid-state ${ }^{15} \mathrm{~N}$ CP-MAS and CP NMR, respectively, for a series of polypeptides $\left[\mathrm{Ala}^{*}, \mathrm{X}\right]_{\mathrm{n}}$ containing ${ }^{15} \mathrm{~N}$-labeled L-alanine $\left(\mathrm{Ala}^{\star}\right)$ and other amino acids (X: residues with a natural abundance of ${ }^{15} \mathrm{~N}$ ), such as glycine, L-alanine, D-alanine, L-valine, $\beta$-benzyl-Laspartate, and so on. The conformations for these polypeptides are characterized on the basis of their conformation-dependent ${ }^{13} \mathrm{C}$ chemical shifts. ${ }^{58}$ It has been demonstrated that the $\delta_{\text {iso }}$ is useful for the conformational study of copolypeptides with identical primary structures (amino-acid sequences), and in addition, the $\delta_{22}$ value of the $\mathrm{Ala}^{*}$ residue in a copolypeptide is closely related to the mainchain conformations (such as the right-handed and left-handed $\alpha$-helices and $\beta$-sheet forms) rather than the amino-acid sequence. Thus, the ${ }^{15} \mathrm{~N}$ chemical shifts of solid polypeptides is conformationdependent. 59

\section{Conformation-dependent ${ }^{17} \mathrm{O}$ chemical shifts}

Conformation-dependent ${ }^{17} \mathrm{O}$ NMR chemical shifts of the amide carbonyl carbons of the Gly residue of solid polyglycine with the $3_{1}$-helix and $\beta$-sheet forms and of the Ala residue of solid poly( $\mathrm{L}$ alanine) with the $\alpha$-helix and $\beta$-sheet forms have been studied to develop a methodology for structural characterization in addition to the analysis of the ${ }^{13} \mathrm{C}$ and ${ }^{15} \mathrm{~N}$ nuclei of the amino-acid residues of polypeptides. ${ }^{60}$ To accomplish this, we must overcome two difficult problems. The first problem is that the ${ }^{17} \mathrm{O}$ nucleus has a very low natural abundance of $0.037 \%$. The second problem is that because the ${ }^{17} \mathrm{O}$ nuclear spin number is $5 / 2$, the quadrupolar splitting of the carbonyl oxygen of the amino-acid residue in solids is very large and thus the amide ${ }^{17} \mathrm{O}$ signal is extremely broad. This implies that it is not easy to determine reliable ${ }^{17} \mathrm{O}$ chemical shift in solids. For this 
Table 1 Conformation-dependent ${ }^{13} \mathrm{C}$ chemical shifts of amino-acid residues in solid polypeptides (p.p.m. from tetramethylsilane) $)^{a, b}$

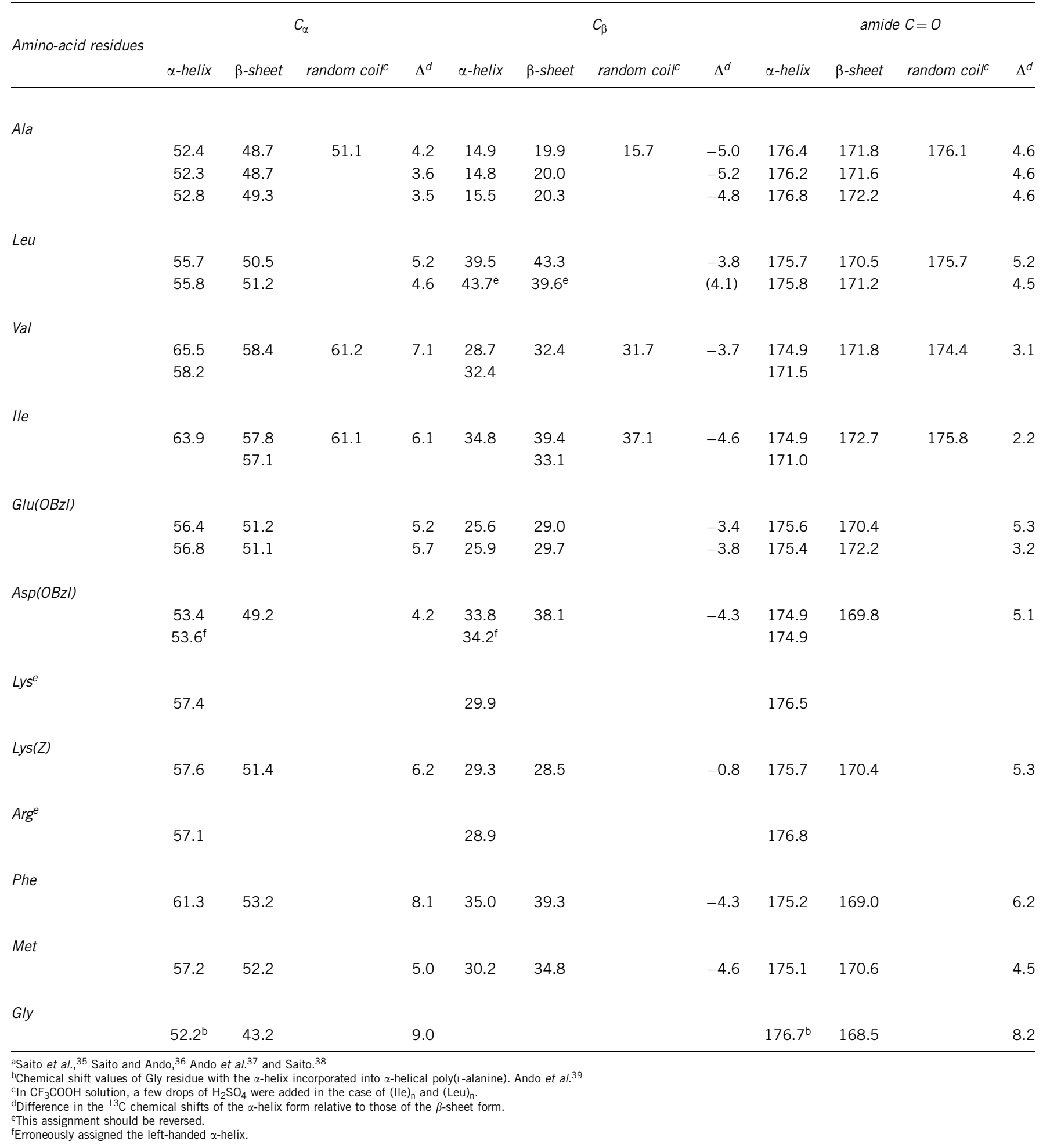

reason, we have developed an ${ }^{17} \mathrm{O}$-labelling method for preparing polyglycine and poly(L-alanine) with $6 \%$ and $10 \%{ }^{17} \mathrm{O}$-labeled amide carbonyl oxygens of the Gly and Ala residues, respectively, ${ }^{60-62}$ and have performed solid-state ${ }^{17} \mathrm{O}$ NMR measurements with different NMR frequencies ${ }^{61,63,64}$ and with high NMR frequency and highspeed MAS ${ }^{64,65}$ and performed ${ }^{17} \mathrm{O}$ spectral analysis. ${ }^{66}$
Solid-state ${ }^{17} \mathrm{O}$ NMR spectra of Gly- and Ala-containing peptides and polypeptides have been measured by using the static CP method at certain NMR frequencies $\left(270,400\right.$ and $500 \mathrm{MHz}$ for $\left.{ }^{1} \mathrm{H}\right) .{ }^{61}$ The chemical shift $(\delta)$, quadrupolar coupling constant $\left(e^{2} q Q / h\right)$ and asymmetric parameter of the electric field gradient $(\eta)$ have been determined by computer simulations of the obtained spectra. First, 
the isotropic chemical shifts and tensor components are employed. From the static CP experiments, it was determined that the $\delta_{\text {iso }}$ values for the $3_{1}$-helix and $\beta$-sheet forms in polyglycine ${ }^{61}$ are 288 and 299 p.p.m., respectively, relative to external liquid water ( $\delta=0$ p.p.m.), and thus the $3_{1}$-helix form appears at a higher field by 11 p.p.m. than the $\beta$-sheet form. The static CP experiments also determined that the $\delta_{\text {iso }}$ values for the $\alpha$-helix and $\beta$-sheet forms in poly(L-alanine $)^{63}$ are 303 and 265 p.p.m., respectively, and thus the $\alpha$-helix form appears at a lower field by 38 p.p.m. than the $\beta$-sheet form. This indicates that the ${ }^{17} \mathrm{O} \delta_{\text {iso }}$ is very sensitive to the secondary structure and thus is conformation dependent. Furthermore, we are concerned with the tensor components $\left(\delta_{11}, \delta_{22}\right.$ and $\delta_{33}$, from downfield to upfield), although the experimental errors are not so small due to the broad spectra. It has been determined that the tensor components $\left(\delta_{11}, \delta_{22}\right.$ and $\left.\delta_{33}\right)$ for the $\beta$-sheet and $3_{1}$-helix forms in polyglycine $^{61}$ are $(574,425$ and -101 p.p.m.) and $(562,410$ and -108 p.p.m.), respectively, and that the tensor components $\left(\delta_{11}, \delta_{22}\right.$ and $\left.\delta_{33}\right)$ for the $\alpha$-helix and $\beta$-sheet forms in poly(L-alanine) $)^{63}$ are (595, 435 and -121 p.p.m.) and (514, 390 and -110 p.p.m.), respectively. From these experimental results, it is seen that all of the tensor components for the $\beta$-sheet form in polyglycine appear at a lower field than the $3_{1}$-helix form in polyglycine, and in poly $(\mathrm{L}-$ alanine), the $\delta_{11}$ and $\delta_{22}$ for the $\alpha$-helix form appear at a lower field than the $\beta$-sheet form, and the $\delta_{33}$ for the $\alpha$-helix form appears at a higher field than for the $\beta$-sheet form.

Furthermore, to determine the exact isotropic ${ }^{17} \mathrm{O}$ chemical shift value, a combination of high-field magnetic and high-speed MAS methods has been used. As one example, the high-resolution solidstate NMR spectra of solid poly(L-alanine)s with the $\alpha$-helix and $\beta$-sheet forms have been measured by using a high-field magnet $\left(800 \mathrm{MHz}\right.$ for $\left.{ }^{1} \mathrm{H}\right)$ and a high-speed MAS $(25 \mathrm{kHz})$ as shown in Figure $1 .{ }^{64}$ The $\delta_{\text {iso }}$ values for the $\alpha$-helix and $\beta$-sheet forms have been determined to be 319 and 286 p.p.m., respectively. It is shown that the $\alpha$-helix form appears at a lower field by 33 p.p.m. than the $\beta$-sheet form. These values are approximately those determined by the static $\mathrm{CP}$ method. It is seen from these results that the conformationdependent ${ }^{17} \mathrm{O}$ chemical shift is remarkably larger than the corresponding conformation-dependent ${ }^{13} \mathrm{C}$ and ${ }^{15} \mathrm{~N}$ chemical shifts. However, the $\delta_{\text {iso }}$ values for the $3_{1}$-helix and $\beta$-sheet forms in solid polyglycine are determined to be 293 and 304 p.p.m., respectively. It is shown that the $3_{1}$-helix form appears at a higher field by 11 p.p.m. than the $\beta$-sheet form. From these results, it is seen that these values are approximately those determined by static $\mathrm{CP}$ method. Furthermore, we can obtain the $e^{2} q Q / h$ value from the observed ${ }^{17} \mathrm{O}$ NMR spectral analysis. It has been determined that the $e^{2} q \mathrm{Q} / h$ values for the $\alpha$-helix and $\beta$-sheet forms in poly(L-alanine) are 8.59 and $8.04 \mathrm{MHz}$, respectively, and those for the $3_{1}$-helix and the $\beta$-sheet forms in polyglycine are 8.21 and $8.36 \mathrm{MHz}$, respectively. The $e^{2} q Q / h$ will be discussed as related to the length of the amide hydrogen bond $>\mathrm{C}=\mathrm{O} \cdot \cdots \mathrm{H}-\mathrm{N}<^{67-69}$ and the experimental results $^{64,65}$ and theoretical calculations ${ }^{66}$ will be compared under the section head Isotropic ${ }^{1} \mathrm{H}$ chemical shifts.

Lemaitre et al. ${ }^{70}$ measured the solid-state MAS ${ }^{17} \mathrm{O}$ NMR spectra of a selectively labeled transmembrane peptide, ${ }^{17} \mathrm{O}$-[L-Ala12]-WALP23, that was single-labeled at Ala-12 as a lyophilized powder and incorporated in hydrated vesicles at 81.345 and $108.419 \mathrm{MHz}$. The spectral pattern is very similar to that of $(\mathrm{Ala})_{\mathrm{n}}$ with the $\alpha$-helix form. ${ }^{64}$ The isotropic chemical shift for the labeled peptide at 317.5 p.p.m. is very close to that of $(\mathrm{Ala})_{\mathrm{n}}$ with the $\alpha$-helix form at 319 p.p.m., therefore, the peptide takes the $\alpha$-helix form. The MAS ${ }^{17} \mathrm{O}$ spectrum was measured at $81.345 \mathrm{MHz}$ for ${ }^{17} \mathrm{O}$-[L-Ala12]-
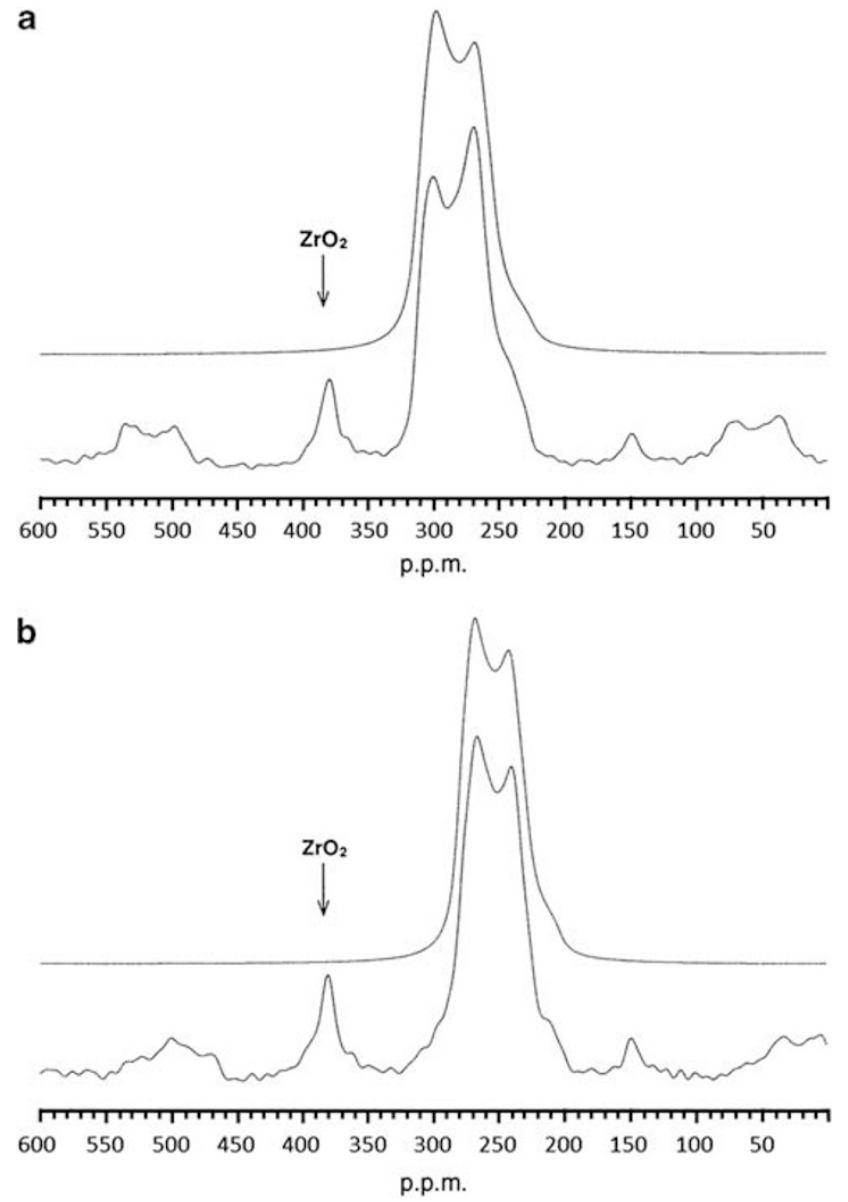

Figure 1 The observed and theoretically simulated MAS ${ }^{17} \mathrm{O}$ (a) NMR spectra spun at $25 \mathrm{kHz}$ for solid (L-Ala) $\mathrm{n}$, (b) $n=100$, with an $\alpha$-helix form and solid (L-Ala),$n=5$, with a $\beta$-sheet form at $108.6 \mathrm{MHz}(800 \mathrm{MHz}$ for $\left.{ }^{1} \mathrm{H}\right)$ at room temperature. From Yamauchi et al.64

WALP23 in hydrated DSPC vesicles (1:10 peptide/lipid molar ratio) with a single resonance from the label inserted in alanine- 12 centered at approximately 280 p.p.m. The lyophilized MLV sample was hydrated with one weight equivalent of water, and the spectrum was acquired at room temperature with the lipids in the liquid crystalline phase. Recently, the number of solid-state ${ }^{17} \mathrm{O} N \mathrm{NM}$ studies on the structures of various types of peptides and biomolecules has been increasingly reported.

\section{Conformation-dependent ${ }^{1} \mathbf{H}$ chemical shifts}

Shoji et al. ${ }^{71,72}$ showed using ${ }^{1} \mathrm{H}$ CRAMPS (combined rotation and multiple pulse spectroscopy) measurements on various homopolypeptides in the solid state that the ${ }^{1} \mathrm{H}$ chemical shifts of the $\mathrm{H}_{\alpha}$ signal of homopolypeptides with the $\alpha$-helix and $\beta$-sheet forms are 3.9-4.0 p.p.m. and 5.1-5.5 p.p.m., respectively, relative to tetramethylsilane. Thus, the solid-state ${ }^{1} \mathrm{H}$ chemical shift is as conformation-dependent as the ${ }^{13} \mathrm{C},{ }^{15} \mathrm{~N}$ and ${ }^{17} \mathrm{O}$ chemical shifts, which is very useful for conformational analysis of polypeptides in the solid state.

Yamauchi et al. ${ }^{73,74}$ developed a new NMR technique for measuring high-resolution solid-state ${ }^{1} \mathrm{H}$ NMR by using the FSLG-2 (frequencyswitched Lee-Goldburg) homonuclear dipolar decoupling method combined with high-speed MAS and have carried out the structural characterization of polypeptides in the solid state, as described below. 
By using this technique, the structural characterization of Nylon 6, a polyamide, in the solid state has been performed by measuring solidstate ${ }^{1} \mathrm{H}$ NMR spectra over a wide range of temperatures. ${ }^{75}$

\section{CONCEPT OF NMR CHEMICAL SHIFT MAP}

In the crystalline state, structural information obtained from the chemical shift of polypeptides corresponds to the fixed conformation as mentioned above. The calculation of the ${ }^{13} \mathrm{C}$ chemical shifts for the dipeptide fragments ( $N$-acetyl- $N^{\prime}$-methyl-L-alanineamide) [Ac-L-Ala$\mathrm{NHMe}$ of poly(L-alanine) and L-alanine residues containing proteins has been attempted using the FPT (finite perturbation theory) INDO method as functions of the dihedral angles $(\Phi, \Psi)$, varied in $15^{\circ}$ intervals. A contour map has been made as a function of $\Phi$ and $\Psi$ in the transversal and longitudinal axes, respectively, for the ${ }^{13} \mathrm{C}$ chemical shift using the obtained chemical shift values to understand and predict the ${ }^{13} \mathrm{C}$ chemical shift behavior of polypeptides associated with the secondary structure elements, such as the $\alpha$-helix, $\beta$-sheet, and so on. ${ }^{76}$ This chemical shift map is a very useful representation of the chemical shift behavior resulting from changing the dihedral angles as in a Ramachandran energy map. By comparing the experimental data and the predicted values given by this chemical shift map, the ${ }^{13} \mathrm{C}$ chemical shifts of Ala residues in polypeptides and proteins can be successfully predicted. This has been used to understand the ${ }^{13} \mathrm{C}$ chemical shift behavior of collagen protein ${ }^{42}$ and silk proteins ${ }^{45}$ in the solid state.

Furthermore, $a b$ initio calculations for the NMR chemical shifts have become available for medium-size molecules as a consequence of remarkable advances in the performance of workstations, personal computers and supercomputers. This allows for a quantitative discussion on the chemical shift behavior. As an example, the $a b$ initio MO calculation with the 4-31G basis set using the GIAO-CHF (gauge-independent atomic orbital-coupled Hartree-Fock) method was carried out on $N$-acetyl- $N^{\prime}$-methyl-L-alanineamide, the same model molecules as the case of the above FPT INDO calculation. ${ }^{77}$ The isotropic ${ }^{13} \mathrm{C}$ chemical shift map of the $\mathrm{C}_{\beta}$ carbon as a function of the dihedral angles $(\Phi, \Psi)$ was calculated as shown in Figure 2, where the positive sign indicates shielding. The overall trend of this map is similar to that obtained by the FPT INDO method. The calculated isotropic chemical shift $(\sigma)$ for the $\mathrm{C}_{\beta}$ carbon are 186.4 p.p.m. for the dihedral angles $(\Phi, \Psi)$ corresponding to the anti-parallel $\beta\left(\beta_{\mathrm{A}}\right)$-sheet form, 189.4 p.p.m. for the right-handed $\alpha\left(\alpha_{\mathrm{R}}\right)$-helix form and 189.6 p.p.m. for the left-handed $\alpha\left(\alpha_{\mathrm{L}}\right)$-helix form, and the observed isotropic chemical shifts $(\delta)$ are 21.0 p.p.m. for the $\beta_{\mathrm{A}}$-sheet form, 15.5 p.p.m. for the $\alpha_{\mathrm{R}}$-helix form and 15.9 p.p.m. for the $\alpha_{\mathrm{L}}$-helix form. Such experimental chemical shift behavior is well explained by the calculated chemical shift behavior. It is found that the changes in the dihedral angles $(\Phi, \Psi)$ dominate the isotropic chemical shift behavior of the $\mathrm{C}_{\beta}$ carbon of the L-alanine residue.

As mentioned above, the principal values of the chemical shift tensor provide information about the $3 \mathrm{D}$ electronic state of a molecule. However, to understand the behavior of the principal values, one should obtain information about the orientation of the principal axis system of the chemical shift tensor with respect to the molecular fixed frame. The orientations of the principal axis systems of the chemical shift tensors of the $\mathrm{C}_{\beta}$-carbons in Ala have been calculated for some peptides whose Ala moieties have different mainchain dihedral-angles: $(\Phi, \Psi)=\left(-57.4^{\circ},-47.5^{\circ}\right)\left(\alpha_{\mathrm{R}}\right.$-helix form $)$, $\left(-138.8^{\circ}, 134.7^{\circ}\right)\left(\beta_{\mathrm{A}^{-}}\right.$sheet form $),\left(-66.3^{\circ},-24.1^{\circ}\right)\left(3_{10}{ }^{\mathrm{R}}\right.$-helix form $)$ and $\left(-84.3^{\circ}, 159.0^{\circ}\right)\left(3_{1}\right.$-helix form). The $\sigma_{33}$ component nearly lies along the $\mathrm{C}_{\alpha}-\mathrm{C}_{\beta}$ bond for all the peptides considered here,

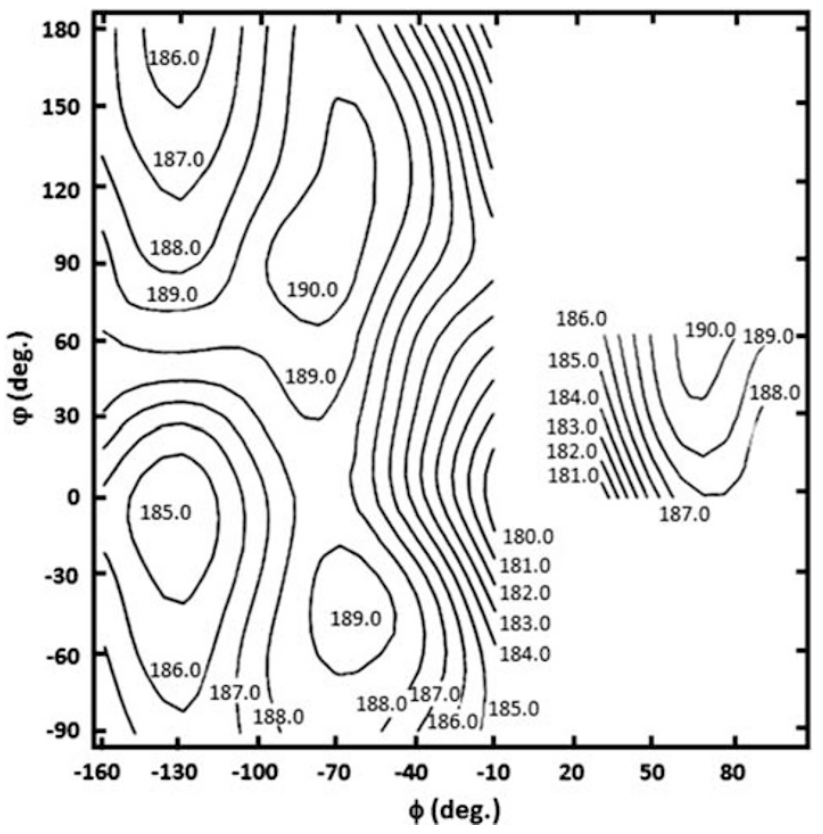

Figure 2 The isotropic ${ }^{13} \mathrm{C}$ chemical shift contour map for the $\mathrm{C}_{\beta}$ carbon of the L-alanine residue with the dihedral angles $(\Phi, \Psi)$ calculated by using the GIAO-CHF method with the 4-31 G ab initio basis set according to the concept of the NMR chemical shift map, ${ }^{76}$ in p.p.m. The $4-31 \mathrm{G}$ basis set optimized the geometries for the model molecules, $N^{\prime}$-acetyl- $N$-methyl-Lalanine amide. From Asakawa et al. ${ }^{77}$

and the $\sigma_{11}$ is nearly also perpendicular to the plane defined by the $\mathrm{C}_{\beta}, \mathrm{C}_{\alpha}$, and $\mathrm{N}$ atoms in the Ala residue. ${ }^{78}$ The $\sigma_{22}$ component is parallel to the plane. These results agree with the experimentally determined direction of the $\sigma_{33}$ for the $\mathrm{C}_{\beta}$-carbon in the L-Ala aminoacid residue by Naito et al. ${ }^{79}$ The $\sigma_{11}$ component for the dihedral angles corresponding to the $\beta_{\mathrm{A}}$-sheet form is 37.06 p.p.m. This shows a downfield shift of approximately 9 p.p.m. with respect to that for the $\alpha_{\mathrm{R}}$-helix form. This means that the $\sigma_{11}$ dominates the downfield shift on the isotropic chemical shift of the $\mathrm{C}_{\beta}$ carbon for the $\beta_{\mathrm{A}}$-sheet form. Because the $\sigma_{11}$ is not oriented along a specified chemical bond, it is not easy to intuitively comprehend the chemical shift tensor behavior of the $\mathrm{C}_{\beta}$ carbon. However, it is obvious that the through-space interaction between the $\mathrm{C}_{\beta}$ methyl group and its surroundings might be important for understanding the $\sigma_{11}$ behavior.

For all of the dihedral angles employed in the calculations, the $\sigma_{33}$ component of the chemical shift tensor of L-alanine $\mathrm{C}_{\alpha}$-carbons lies approximately along the $\mathrm{C}_{\alpha}-\mathrm{C}^{\prime}(=\mathrm{O})$ bond. However, for the dihedral angles $(\Phi, \Psi)=\left(-57.4^{\circ},-47.5^{\circ}\right)\left(\alpha_{\mathrm{R}}\right.$-helix form $),\left(-66.3^{\circ},-24.1^{\circ}\right)$ $\left(3_{10}{ }^{\mathrm{R}}\right.$-helix form $)$ and $\left(-84.3^{\circ}, 159.0^{\circ}\right)\left(3_{1}\right.$-helix form $)$, the $\sigma_{22}$ component diverges slightly from the $\mathrm{C}_{\alpha}-\mathrm{C}_{\beta}$ bond and for $(\Phi$, $\Psi)=\left(-138.8^{\circ}, 134.7^{\circ}\right)\left(\beta_{\mathrm{A}}\right.$-sheet form $)$, the $\sigma_{11}$ component is along this direction. The tensor component that is nearly along the $\mathrm{C}_{\alpha}-\mathrm{C}_{\beta}$ bond is 47.53 p.p.m. for the $\beta_{\mathrm{A}}$-sheet form, 61.93 p.p.m. for the $\alpha_{\mathrm{R}}$-helix form, 64.74 p.p.m. for the $3_{10}{ }^{\mathrm{R}}$-helix form and 65.79 p.p.m. for the $3{ }_{1}$-helix form. Changes in the dihedral angles cause a large deviation of the chemical shift tensor component that is along the $\mathrm{C}_{\alpha}-\mathrm{C}_{\beta}$ bond. Moreover, because the $\sigma_{33}$ depends on changes from one dihedral angle to another, it is obvious that the dihedral angle is explicitly dependent on the $\sigma_{33}$. It is thought that if the carbonyl group in the Ala residue forms a hydrogen bond, the $\sigma_{33}$ will be most likely affected. de Dios et al. ${ }^{80}$ studied the ${ }^{13} \mathrm{C}$ chemical shift behavior 
of polypeptides and proteins by using $a b$ initio $\mathrm{MO}$ calculation of the ${ }^{13} \mathrm{C}$ chemical shifts of several types of oligo-peptides such as in the representation of the FPT INDO ${ }^{13} \mathrm{C}$ chemical shift map as a function of the dihedral angles.

Another significant and empirical correlation of the ${ }^{13} \mathrm{C}$ chemical shift map has been made by Spera and $\mathrm{Bax}^{81}$ on the basis of a database of the experimental ${ }^{13} \mathrm{C}$ chemical shift values of 442 residues of various globular proteins in solution for which the dihedral angles $(\Phi, \Psi)$ are known with good precision by X-ray work, resolved at 1.0-2.2 $\AA$. Their ${ }^{13} \mathrm{C}$ chemical shift maps of the $\mathrm{C}_{\alpha}$ and $\mathrm{C}_{\beta}$ carbons show the distribution of the secondary shifts in the $\alpha$-helix and $\beta$-sheet forms. These are consistent with the solid state ${ }^{13} \mathrm{C}$ chemical shifts of homopolypeptides. For the $\mathrm{C}_{\alpha}$ carbon, the average secondary shift for the $\alpha$-helix form (119 residues) appears at a lower field by approximately 4.6 p.p.m. compared with the $\beta$-sheet form (126 residues), and for the $\mathrm{C}_{\beta}$ carbon, the former appears at a higher field by approximately 2.6 p.p.m. The chemical shift dispersion collected from globular proteins in solution is much larger than that from solid polypeptides. In addition, the database, containing $3796{ }^{13} \mathrm{C}_{\alpha}$ chemical shifts and $2794{ }^{13} \mathrm{C}_{\beta}$ chemical shifts as obtained from 40 different proteins, was used for the preparation of the chemical shift maps by Asakura et al. ${ }^{82,83}$ It is shown that the chemical shift map is useful for the structural characterization of proteins, and the solution conformation of the protein is essentially similar to that in the solid state.

\section{NMR CHEMICAL SHIFTS AND HYDROGEN-BONDED STRUCTURES ASSOCIATED WITH THE SECONDARY STRUCTURE OF SOLID PEPTIDES AND POLYPEPTIDES}

It is well known that hydrogen bonds have an important role in forming the secondary structures of peptides and polypeptides, including proteins. Thus, the nature of the hydrogen bond has been widely studied by various spectroscopic methods. ${ }^{84}$ High-resolution NMR spectroscopy has also been used as one of the most powerful means for obtaining useful information about details of the hydrogenbonded structure as associated with the secondary structure. Therefore, the chemical shifts of the amide carbonyl carbon, amide nitrogen, amide carbonyl oxygen and amide hydrogen of the aminoacid residues associated with hydrogen bonding have provided useful information about the secondary structure of polypeptides. ${ }^{85}$

The NMR chemical shift is one of the most important parameters for providing information about molecular structures including hydrogen bonds. Because the electronic structure around the amide carbonyl-carbon and nitrogen in peptides and polypeptides is greatly affected by the nature of the hydrogen bond, the NMR chemical shifts for the nuclei involved are sensitive to the spatial arrangement of the nuclei comprising the hydrogen bond.

However, it is difficult to exactly determine the effect of hydrogen bonding on the chemical shifts in solution because the observed chemical shifts of peptides are often the averaged value over rotational isomers resulting from the interconversion caused by rapid rotations about the bonds. In contrast, the chemical shifts in the solid state provide direct information about the hydrogen bond of the peptides and polypeptides with a fixed conformation. Taking advantage of this, systematic studies have been performed on the effect of hydrogen bonding on the chemical shifts of the amide carbonyl carbon, amide nitrogen, amide oxygen and amide hydrogen of the amino acid residues for peptides and polypeptides in the solid state to obtain detailed information about the hydrogen-bonded structure. ${ }^{85}$ In this section, some of the studies on the hydrogen-bonded structure of peptides and polypeptides in the solid state based on measurements and theoretical calculations of NMR chemical shifts will be discussed. ${ }^{59,85-87}$

Isotropic ${ }^{13} \mathrm{C}$ chemical shifts and chemical shift tensor components The effect of hydrogen bonding on the ${ }^{13} \mathrm{C}$ chemical shift of the carbonyl carbon has been studied in several amino-acid residues. ${ }^{88-92}$ The observed isotropic chemical shifts $\left(\delta_{\text {iso }}\right)$ of the amide $\mathrm{C}=\mathrm{O}$ carbons of the Gly, L-Ala, L-Val, L-Leu and L-Asp residues of peptides and polypeptides in the solid state were plotted against the $\mathrm{N} \cdots \mathrm{O}$ hydrogen bond length $\left(\mathrm{R}_{\mathrm{N}} \ldots \mathrm{O}\right)$, as shown in Figure 3. This figure shows that a decrease in $\mathrm{R}_{\mathrm{N}}$. . o leads to a downfield shift. There is an approximately linear relationship between $\delta_{\text {iso }}$ and $\mathrm{R}_{\mathrm{N}} \ldots \mathrm{O}$ for the peptides considered here, expressed as $\delta_{\text {iso }}=a-b \mathrm{R}_{\mathrm{N}} \ldots \mathrm{O}$, where $\delta_{\text {iso }}$ is expressed in p.p.m., $\mathrm{R}_{\mathrm{N}} \ldots \mathrm{O}$ is in $\AA$, and $a$ (in p.p.m.) and $b$ (in p.p.m./A) are constant. The values of $a$ and $b$ were calculated to be 206.0 and 12.4 for the Gly residue, 237.5 and 21.7 for the Ala residues, 202.2 and 10.0 for the Leu residue, 215.4 and 14.2 for the Val residue and 199.0 and 9.6 for the Asp residues, respectively, by using the least squares method. There is also an approximately linear relationship between the $\delta_{22}$ and $\mathrm{R}_{\mathrm{N}} \ldots \mathrm{o}$ for the Gly and Ala residues, and the values of $a$ and $b$ were calculated to be 262.9 and 30.2 for the Gly residue and 344.7 and 54.5 for the Ala residue, respectively.

These relationships indicate that the hydrogen bond length can be determined through the observation of the ${ }^{13} \mathrm{C}$ chemical shift of the carbonyl carbon in the amino acid residues in peptides and polypeptides. The slope $b$ of the variation of $\delta_{\text {iso }}$ against the hydrogen bond length for these amino acid residues decreases in the order Ala $>$ Val $>$ Gly $>$ Leu $\approx$ Asp. The magnitude of the intercept decreases in the order Ala $>\mathrm{Val}>\mathrm{Gly}>\mathrm{Leu} \approx \mathrm{Asp}$. The magnitude of the slope $b$ decreases in the same order as the intercept $a$. These results show that the values of $a$ and $b$ are characteristic of individual amino-acid residues. It is noted that the amide carbonyl carbon chemical shifts

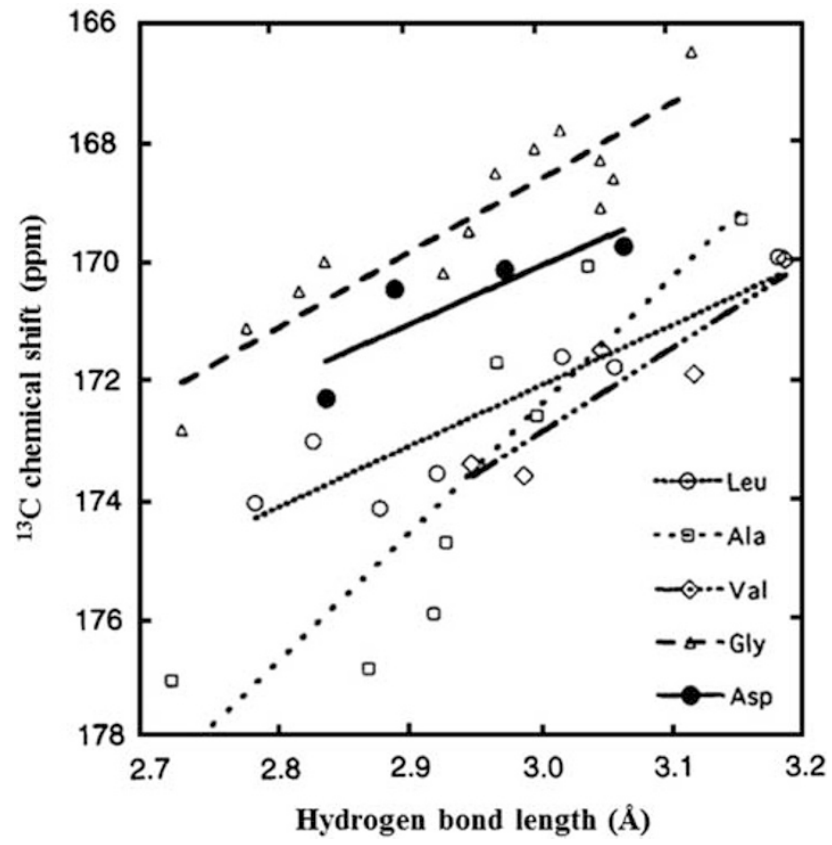

Figure 3 The correlation between the ${ }^{13} \mathrm{C}$ chemical shifts of the amide carbonyl carbons in Gly, L-Ala, L-Val, L-Leu and L-Asp residues of oligopeptides and polypeptides in the solid state and the hydrogen bond length between the amide nitrogen and the amide carbonyl oxygen $\left(R_{N} \ldots O\right)$. ${ }^{13} \mathrm{C}$ chemical shifts are in p.p.m. relative to tetramethylsilane. From Tsuchiya et al.90 
show this hydrogen bond length dependence not only in oligopeptides but also in polypeptides, such as polyglycine and poly(L-alanine). This suggests that the ${ }^{13} \mathrm{C}$ chemical shift of any amino acid carbonylcarbon that accepts the hydrogen bond which is formed between the amide $>\mathrm{C}=\mathrm{O}$ and amide $>\mathrm{N}-\mathrm{H}$ is strongly influenced by the hydrogen bond length.

Some Gly-containing peptides in the crystalline state have a hydrogen bond between the $>\mathrm{C}=\mathrm{O}$ and $-\mathrm{NH}_{3}{ }^{+}$, where the $\mathrm{N}$-terminus is protonated as $\mathrm{NH}_{3}{ }^{+}$and the C-terminus is unprotonated. ${ }^{88}$ The carbonyl ${ }^{13} \mathrm{C}$ chemical shifts are linearly displaced upfield with decreasing $\mathrm{R}_{\mathrm{N}} \cdots \mathrm{O}$, in contrast to the $>\mathrm{C}=\mathrm{O} \cdots \mathrm{H}$ $\mathrm{N}<$ hydrogen bond. Next, we consider the ${ }^{13} \mathrm{C}$ chemical shift calculations for the amide carbonyl carbons of some amino-acid residues by using the corresponding dipeptide hydrogen bonded with two formamide molecules in the calculations utilizing the FPT INDO method as a function of $\mathrm{R}_{\mathrm{N}} \ldots \mathrm{O}^{88}$ The theoretical calculations show that the isotropic ${ }^{13} \mathrm{C}$ chemical shifts for all of the amino-acid residues exhibit approximately linear downfield shifts for short $\mathrm{R}_{\mathrm{N}} \ldots \mathrm{O}$ values. This experimental finding should be reasonably explained by the calculated results in the $\mathrm{R}_{\mathrm{N}} \ldots \mathrm{O}$ region. However, the ${ }^{13} \mathrm{C}$ chemical shifts of the carbonyl carbon of the $N$-acetyl- $N^{\prime}$ methylglycineamide hydrogen bond between the $>\mathrm{C}=\mathrm{O}$ and $-\mathrm{NH}_{3}{ }^{+}$are calculated as a function of the hydrogen bond length. The ${ }^{13} \mathrm{C}$ chemical shift moves upfield for decreasing values of $\mathrm{R}_{\mathrm{N}} \ldots \mathrm{O}$, agreeing with the experimental results. This trend is opposite to that for found peptides that have hydrogen bonds between the amide $>\mathrm{C}=\mathrm{O}$ and $\mathrm{H}-\mathrm{N}<$ groups.

Let us consider the ${ }^{13} \mathrm{C}$ chemical shift tensor behavior of the amide carbonyl carbon of peptides with a hydrogen-bonded structure. It has been reported that the $\delta_{11}$ component is in the amide $s p^{2}$ plane and lies along a direction normal to the $\mathrm{C}=\mathrm{O}$ bond, the $\delta_{22}$ component lies almost along the amide $\mathrm{C}=\mathrm{O}$ bond, and the $\delta_{33}$ component is aligned perpendicular to the amide $s p^{2}$ plane. ${ }^{88,89}$ It is expected that the principal values of the ${ }^{13} \mathrm{C}$ chemical shift tensors $\left(\delta_{11}, \delta_{22}\right.$ and $\left.\delta_{33}\right)$ are, in principle, more valuable as parameters for obtaining the detailed information about the hydrogen bonding that can be used to determine the electronic structure compared with the isotropic ${ }^{13} \mathrm{C}$ chemical shift $\left(\delta_{\text {iso }}=\left(\delta_{11}+\delta_{22}+\delta_{33}\right) / 3\right)$.

The exact tensor components were determined from the HerzfeldBerger analysis ${ }^{93}$ of the spinning side bands of the ${ }^{13} \mathrm{C} \mathrm{CP}$ - slow MAS NMR spectra of carbonyl ${ }^{13} \mathrm{C}$-labeled Ala-containing peptides, such as AcAlaNHMe, AcAlaAibOMe, AlaGlyGly $\cdot \mathrm{H}_{2} \mathrm{O}$, AlaSer and AlaPro$\mathrm{Gly} \cdot \mathrm{H}_{2} \mathrm{O}$, and poly(L-alanine) with the $\alpha$-helix form. ${ }^{89}$ The experimental $\delta_{22}$ values are the most sensitive to $\mathrm{R}_{\mathrm{N}} \ldots \mathrm{O}$, and the $\delta_{22}$ values move linearly downfield with decreasing $\mathrm{R}_{\mathrm{N}} \ldots \mathrm{O}$, except for the $\delta_{22}$ of AlaProGly $\cdot \mathrm{H}_{2} \mathrm{O}$; the covalent bond between the Ala and Pro residues of AlaProGly $\cdot \mathrm{H}_{2} \mathrm{O}$ does not form a peptide bond but an imide bond. For this, the electronic structure of the Ala carbonylcarbon in AlaProGly $\cdot \mathrm{H}_{2} \mathrm{O}$ is thought to be different from that of the Ala carbonyl-carbon forming the peptide bond, and hence, the chemical shift for the Ala carbonyl-carbon might be sensitive to both the $\mathrm{R}_{\mathrm{N}} \ldots \mathrm{O}$ and the nature of the bonds. A decrease in $\mathrm{R}_{\mathrm{N} \ldots \mathrm{O}}$ leads to a slight upfield shift in the $\delta_{11}$, except for AlaProGly $\cdot \mathrm{H}_{2} \mathrm{O}$. The experimental $\delta_{33}$ values are almost independent of $\mathrm{R}_{\mathrm{N}} \ldots \mathrm{O}$, with some scatter on the data. With a decrease in $\mathrm{R}_{\mathrm{N}} \ldots \mathrm{O}$, there is a large downfield shift of the isotropic ${ }^{13} \mathrm{C}$ chemical shifts, $\delta_{\text {iso }}$, resulting from the behavior of the $\delta_{22}$ in overcoming that of the $\delta_{11}$. McDermott et al. ${ }^{94}$ obtained similar results on the amide carbonyl carbons of various types of amino acids.

To understand the relationships between the ${ }^{13} \mathrm{C}$ chemical shift and the hydrogen bond length, the FPT INDO calculations on the ${ }^{13} \mathrm{C}$ chemical shift tensor components of some model peptides have been performed. $^{88,89}$ The calculations show that the $\sigma_{22}$ is the most sensitive to a change of $\mathrm{R}_{\mathrm{N}} \ldots \mathrm{O}$ and moves linearly downfield with a decrease in $\mathrm{R}_{\mathrm{N}} \ldots \mathrm{O}$. Correspondingly, the $\sigma_{11}$ increases with a decrease in $\mathrm{R}_{\mathrm{N}} \ldots \mathrm{O}$, whereas the $\sigma_{11}$ is insensitive to changes in $\mathrm{R}_{\mathrm{N}} \ldots \mathrm{O}$. The results of the theoretical calculations are in agreement with the experimental results. Such an agreement indicates that the changes in the ${ }^{13} \mathrm{C}$ chemical shift originate predominately from a change in the electronic state of the amino carbonyl groups caused by the variation in the hydrogen bond length.

Next, we are concerned with the relationship between the carbonyl ${ }^{13} \mathrm{C}$ chemical shifts and the $\mathrm{R}_{\mathrm{N}} \ldots \mathrm{O}$ values for a Gly residue incorporated into $(\mathrm{Ala})_{\mathrm{n}},(\mathrm{Leu})_{\mathrm{n}}$ and $(\mathrm{Val})_{\mathrm{n}}$ to obtain structural information regarding how the corresponding Gly residue is incorporated with the same secondary structure into the host polypeptides. ${ }^{95}$ The $\mathrm{R}_{\mathrm{N}} \ldots \mathrm{O}$ value for the $\alpha_{\mathrm{R}}$-helix form is in the range of approximately $2.7-2.8 \AA$ and that for the $\beta$-sheet form is approximately $3.0 \AA$, as determined from X-ray diffraction. The $\mathrm{R}_{\mathrm{N}} \ldots \mathrm{O}$ values for the guest Gly residue incorporated into host copolypeptides can be determined by using the relation $\delta=a-b$ $\mathrm{R}_{\mathrm{N}} \ldots \mathrm{O}$ and observing the amide carbonyl ${ }^{13} \mathrm{C}$ chemical shifts, $\delta$, of the guest Gly residue. The analysis of the ${ }^{13} \mathrm{C}$ chemical shift of the Gly residue revealed that the hydrogen bond lengths of the guest Gly residue $\left(\mathrm{R}_{\mathrm{N}} \ldots \mathrm{O}\right)$ are both $2.7 \AA$ in $\left(\mathrm{Leu}, \mathrm{Gly}^{*}\right)_{\mathrm{n}}$ and $\left(\mathrm{Ala}, \mathrm{Gly}^{\star}\right)_{\mathrm{n}}$, where the host Leu and Ala residues take the $\alpha_{\mathrm{R}}$-helix form and Gly ${ }^{\star}$ indicates the ${ }^{13} \mathrm{C}$-labeled glycine residue. This is in agreement with the values of 2.7 and $2.8 \AA$ for the host Leu and Ala residues. Therefore, the guest Gly residue is completely incorporated into host polypeptides with the $\alpha_{\mathrm{R}}$-helix form. Similar results are obtained for $\left(\text { Val, } \mathrm{Gly}^{\star}\right)_{\mathrm{n}}$ and $\left(\mathrm{Ala}, \mathrm{Gly}^{\star}\right)_{\mathrm{n}}$ in the $\beta$-sheet form.

Isotropic ${ }^{15} \mathrm{~N}$ chemical shifts and chemical shift tensor components The isotropic ${ }^{15} \mathrm{~N}$ chemical shifts and the tensor components of the glycine residue in a variety of peptides with a terminal Boc group have been measured to clarify the relationship between the ${ }^{15} \mathrm{~N}$ chemical shift (relative to a saturated ${ }^{15} \mathrm{NH}_{4} \mathrm{NO}_{3}$ solution in water) and $\mathrm{R}_{\mathrm{N}} \ldots \mathrm{O} \cdot{ }^{96,97}$ It has been shown that there is a clear relationship between the observed isotropic ${ }^{15} \mathrm{~N}$ chemical shifts $\left(\delta_{\text {iso }}\right)$ of GlyNH in BocGly, BocGlyAla, BocGlyPhe, BocGlyAib and BocGlyProOBzl in the solid state and their $\mathrm{R}_{\mathrm{N}} \ldots \mathrm{O}$ values determined by $\mathrm{X}$-ray diffraction. The $\mathrm{R}_{\mathrm{N}} \ldots \mathrm{O}$ values of the peptides used here are in the 2.95-3.08 $\AA$ range. However, the hydrogen bond angles $(\angle \mathrm{C}=\mathrm{O} \cdots \mathrm{N})$ are somewhat variable and are in the $113-155^{\circ}$ range. The chemical shifts move downfield with a decrease in $\mathrm{R}_{\mathrm{N}} \ldots \mathrm{O}$. The $\delta_{11}$ and $\delta_{33}$ components are more sensitive to a change in $\mathrm{R}_{\mathrm{N}} \ldots$ o than the $\delta_{22}$ component. A change of $0.2 \AA$ in $\mathrm{R}_{\mathrm{N}} \ldots$ o results in a change of 20 p.p.m. in the $\delta_{11}$ and $\delta_{33}$ components but a change of 5 p.p.m. in the $\delta_{22}$ component. However, only the $\delta_{33}$ component moves linearly downfield with a decrease in $\mathrm{R}_{\mathrm{N}} \ldots \mathrm{O}$; in the $\delta_{11}$ and $\delta_{22}$ components, there is no clear relationship with $\mathrm{R}_{\mathrm{N}} \ldots \mathrm{O}$. Such a behavior is governed not only by the hydrogen bond length but also by the hydrogen bond angle. The ${ }^{15} \mathrm{~N}$ chemical shift $\left(\sigma_{\text {iso }}\right)$ and the chemical shift tensor components $\left(\sigma_{11}, \sigma_{22}\right.$ and $\left.\sigma_{33}\right)$ calculated by the FPT INDO method for $N$-acetyl- $N^{\prime}$-methylglycine amide hydrogen bonded with a formamide molecule have shown that the isotropic ${ }^{15} \mathrm{~N}$ chemical shifts move downfield with a decrease in $\mathrm{R}_{\mathrm{N}} \ldots \mathrm{O}$. This explains the experimental results well. Further details of studies of solid-state ${ }^{15} \mathrm{~N}$ NMR chemical shifts associated with hydrogen bonding in peptides and polypeptides are reviewed elsewhere. ${ }^{40,59}$

The directions of the GlyNH ${ }^{15} \mathrm{~N}$ chemical shift tensor components have been determined using a BocGlyGlyGlyOBzl single crystal. ${ }^{98}$ It 
was shown experimentally that the $\sigma_{11}$ component lies approximately along the $\mathrm{N}-\mathrm{H}$ bond, the $\sigma_{22}$ component is aligned in the direction perpendicular to the peptide plane, and the $\sigma_{33}$ component lies

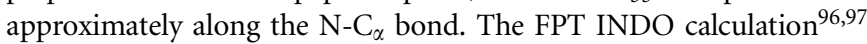
shows that the $\sigma_{11}$ component lies approximately along the $\mathrm{N}-\mathrm{H}$ bond, in agreement with the experimental results, but the $\sigma_{22}$ component lies approximately along the $\mathrm{N}-\mathrm{C}_{\alpha}$ bond and the $\sigma_{33}$ component is aligned in the direction perpendicular to the peptide plane, which are different from the experimental results. It seems that it is not easy to determine the directions of the $\sigma_{22}$ and $\sigma_{33}$ components with significant experimental accuracy because their values are very close to each other. The calculated assignment of the $\sigma_{22}$ and $\sigma_{33}$ components seems to be acceptable, although it is difficult to differentiate between them. The direction of the $\sigma_{11}$ component can be easily determined because its magnitude is significantly different from the others. In the theoretical calculation, the most shielded component $\sigma_{33}$ is aligned in the direction perpendicular to the peptide plane because the orbitals of the nitrogen lone-pair electrons are in this direction. It has been shown from the experimental results that the $\sigma_{33}$ component moves linearly downfield with a decrease in the hydrogen bond length; therefore, the $\sigma_{33}$ component is not related to the hydrogen bond angle and the $\sigma_{11}$ and $\sigma_{22}$ components are related to the hydrogen bond length and the hydrogen bond angle. These have been reasonably explained by the calculation.

Isotropic ${ }^{17} \mathrm{O}$ chemical shifts and chemical shift tensor components In addition to the studies on the conformation-dependent ${ }^{17} \mathrm{O}$ chemical shifts of polyglycine and poly(L-alanine), the association of the hydrogen bond structure with the ${ }^{17} \mathrm{O}$ NMR parameters such as the chemical shifts $\delta_{\text {iso }}$ and $\left(\delta_{11}, \delta_{22}\right.$ and $\left.\delta_{33}\right), e^{2} q Q / h$ and $\eta$ of Glycontaining peptides and polyglycine and poly(L-alanine) in the solid state have been studied. ${ }^{61,63-65}$ Furthermore, these experimental data have been analyzed with the theoretical calculations of the association of the hydrogen-bonded structure with the NMR parameters for $N$-acetyl- $N^{\prime}$-methylglycineamide hydrogen bonded with two formamide molecules by the FPT-MNDO-PM3 method ${ }^{66}$ and the $a b$ initio $\mathrm{MO}$ method $^{99}$ as a function of the hydrogen bond length $\mathrm{R}_{\mathrm{N}} \ldots \mathrm{O}$. The hydrogen bond length is closely related to the higherorder structures, such as the $\alpha$-helix, $3_{1}$-helix, $\beta$-sheet and other forms. The above theoretical calculations predict that the $\delta_{\text {iso }}$ values moves upfield with a decrease in the $\mathrm{R}_{\mathrm{N}} \ldots \mathrm{O}$. It is known from X-ray diffraction studies that the $\mathrm{R}_{\mathrm{N}} \ldots \mathrm{O}$ values for the $\beta$-sheet form ${ }^{100}$ and the 3 -helix form ${ }^{67}$ in polyglycine are 2.95 and $2.73 \AA$, respectively, and the $\mathrm{R}_{\mathrm{N}} \ldots \mathrm{O}$ values for the $\alpha$-helix and $\beta$-sheet forms in poly $(\mathrm{L}$ alanine $)^{68,69}$ are 2.87 and $2.83 \AA$, respectively. Therefore, the experimental finding that the $\beta$-sheet form $\left(\delta_{\text {iso }}=304\right.$ p.p.m. $)$ in polyglycine appears at a lower field by 11 p.p.m. than the $3_{1}$-helix form ( $\delta_{\text {iso }}=293$ p.p.m. $)$ is reasonably explained by the chemical shift calculations. The experimental finding that the $\alpha$-helix form $\left(\delta_{\text {iso }}=319\right.$ p.p.m. $)$ in poly(L-alanine $)$ appears at a lower field by 33 p.p.m. than the $\beta$-sheet form $\left(\delta_{\text {iso }}=286\right.$ p.p.m. $)$ also agrees with the chemical shift calculations on $N$-acetyl- $N^{\prime}$-methylglycineamide.

Furthermore, we are concerned with the experimental ${ }^{17} \mathrm{O}$ chemical shift tensor components $\left(\delta_{11}, \delta_{22}\right.$ and $\left.\delta_{33}\right)$ for the Gly residues of the Gly-containing peptides (GlyGly and GlyGly $\cdot \mathrm{HNO}_{3}$ ) and polyglycine. It has been shown that all of the tensor components move to a high field with a decrease in $\mathrm{R}_{\mathrm{N}} \ldots \mathrm{O} \cdot{ }^{60}$ However, the hydrogen bond length dependence of the calculated chemical shift tensor components of the Gly carbonyl oxygen for the model molecule system of $\mathrm{N}$ acetyl- $N^{\prime}$-methylglycine amide hydrogen bonded with two formamide molecules shows that all of the tensor components move largely downfield with an increase in $\mathrm{R}_{\mathrm{N}} \ldots \mathrm{O}$. This qualitatively explains the experimental trend.

The plots of the experimental $e^{2} q Q / h$ values for the Gly residues of the Gly-containing peptides (GlyGly and GlyGly $\cdot \mathrm{HNO}_{3}$ ) and polyglycine against the hydrogen bond length show that the $e^{2} q \mathrm{Q} / h$ values decrease linearly with a decrease in $\mathrm{R}_{\mathrm{N}} \ldots \mathrm{O}$. This relationship can be expressed by $e^{2} q \mathrm{Q} / \mathrm{h} \quad(\mathrm{MHz})=5.15+1.16 \mathrm{R}_{\mathrm{N}} \ldots \mathrm{O}(\AA) .{ }^{61}$ Such a change results from a change in the $q$ values, which are the largest component of the electric gradient tensor $\left(\mathrm{V}_{33}\right)$. This result shows that the decrease in the hydrogen bond length leads to the decrease of electric gradient. The $q$ value seems to be very sensitive to changes in the hydrogen bonding length.

As mentioned above, it has been shown that the significance of solid-state ${ }^{17} \mathrm{O}$ NMR studies has been revealed in the deeper understanding of the hydrogen-bonded structure of solid biopolymers.

\section{Isotropic ${ }^{1} \mathbf{H}$ chemical shifts}

In addition to the ${ }^{13} \mathrm{C},{ }^{15} \mathrm{~N}$ and ${ }^{17} \mathrm{O} \mathrm{NMR}$ studies on the hydrogenbonded structure, it may be significant to clarify whether there is a relationship between the amide ${ }^{1} \mathrm{H}$ NMR chemical shift and the hydrogen bond length $\mathrm{R}_{\mathrm{N}} \ldots \mathrm{O}$ for peptides and polypeptides in the solid state, and also whether this is supported by theoretical calculations because this information could lead to further elucidation of the hydrogen-bonded structure. However, before doing this experiment, we must overcome some technical NMR problems. For example, it is necessary to reduce the large dipolar interaction between the proton nuclei to obtain a small linewidth. The CRAMPS method is one of the solutions to obtain a ${ }^{1} \mathrm{H}$ NMR spectrum with a reasonable resolution. To obtain a high-resolution ${ }^{1} \mathrm{H}$ NMR spectrum for peptides and proteins in the crystalline state, there are some reports in which a combination of MAS and CRAMPS techniques is used. ${ }^{71,72}$ However, the CRAMPS method requires a slow MAS speed for sampling the data points during acquisition (for example, the BR24 multi-pulse sequence needs less than approximately $3 \mathrm{kHz}$ for sampling). The spinning rate of $3 \mathrm{kHz}$ is not enough to provide a high-resolution ${ }^{1} \mathrm{H}$ NMR spectrum to analyze the amide proton chemical shift in peptides and polypeptides because the amide proton is directly bonded to the quadrupolar ${ }^{14} \mathrm{~N}$ nucleus. As reported by McDermott et al., ${ }^{101,102}$ amino acids take up $\mathrm{NH}_{3}{ }^{+}$forms, so the quadrupolar effect on the proton linewidth by the ${ }^{14} \mathrm{~N}$ becomes very small because of its high symmetry. Therefore, the $\mathrm{NH}_{3}{ }^{+}$proton linewidth in the amino acids become much sharper than that of amide protons in the peptides and polypeptides considered here.

Let us consider the relationship between the $\mathrm{R}_{\mathrm{N}} \ldots \mathrm{O}$ and the hydrogen-bonded amide ${ }^{1} \mathrm{H}$ chemical shift data obtained from highresolution ${ }^{1} \mathrm{H}$ NMR spectra of hydrogen-bonded Gly-containing peptides and polypeptides in the solid state. The ${ }^{1} \mathrm{H}$ NMR spectra was obtained at a high MAS speed of $30 \mathrm{kHz}$ and a high frequency of $800 \mathrm{MHz}$ for the removal of the dipolar coupling and quadrupolar coupling with amide ${ }^{14} \mathrm{~N} .{ }^{73}$ The ${ }^{1} \mathrm{H}$ MAS NMR spectra of Glycontaining peptides and polyglycine show that the amide proton, $\alpha$-proton and side-chain protons are straightforwardly assigned because their peaks are clearly resolved from each other. The amide ${ }^{1} \mathrm{H}$ chemical shift must be carefully assigned. By using an NMR technique to measure the high-resolution solid-state ${ }^{1} \mathrm{H}$ NMR designed with the FSLG-2 homonuclear dipolar decoupling method $^{103-106}$ combined with high-speed MAS, the high-resolution solid-state ${ }^{1} \mathrm{H}$ NMR spectra of amino acids, peptides and polypeptides have been obtained with more reasonable resolution for the amide ${ }^{1} \mathrm{H}$ signals. The chemical shifts of the amide ${ }^{1} \mathrm{H}$ provide 
information about the hydrogen-bonded structure, compared with other high-resolution solid-state ${ }^{1} \mathrm{H}$ NMR methods. ${ }^{74}$ The determined Gly amide ${ }^{1} \mathrm{H}$ chemical shift values of peptides and polypeptides in the solid state were plotted against the $R_{N} \ldots O$ as determined from X-ray diffraction (not shown), and the amide ${ }^{1} \mathrm{H}$ chemical shifts moved downfield with a decrease in $\mathrm{R}_{\mathrm{N}} \ldots \mathrm{O}$. The relation between the amide ${ }^{1} \mathrm{H}$ chemical shifts $\left(\delta_{\mathrm{H}}\right)$ and the $\mathrm{R}_{\mathrm{N}} \ldots \mathrm{O}$ was determined to be $\delta_{\mathrm{H}}=25.4-5.9 \mathrm{R}_{\mathrm{N}} \ldots \mathrm{O}$ (p.p.m.). Therefore, by observing the amide ${ }^{1} \mathrm{H}$ chemical shift value, the value of $\mathrm{R}_{\mathrm{N}} \ldots$ o can be determined. Furthermore, the $a b$ initio MO calculation and the neutron diffraction data show that the reduction of $\mathrm{R}_{\mathrm{N}} \ldots \mathrm{O}$ leads to a decrease in the hydrogen bond length $\left(\mathrm{R}_{\mathrm{O}} \ldots \mathrm{H}\right)$ between the amide hydrogen and the amide carbonyl oxygen. ${ }^{96}$ Thus, the ${ }^{1} \mathrm{H}$ chemical shifts move downfield with a decrease in $\mathrm{R}_{\mathrm{O}} \cdots \mathrm{H}$. The isotropic ${ }^{1} \mathrm{H}$ chemical shifts and the tensor components of hydrogen-bonded Gly amide protons of two hydrogen-bonded GlyGly molecules were also calculated by using the Gaussian 96 program with the $a b$ initio 6-31 $\mathrm{G}^{* *}$ basis set by changing $\mathrm{R}_{\mathrm{N}} \ldots \mathrm{O}$ from 3.5 to $2.6 \AA$ according to its crystal structure as determined by X-ray diffraction. ${ }^{107}$ The calculated chemical shifts move downfield by 2.5 p.p.m. from 6.9 to 9.4 p.p.m. as $\mathrm{R}_{\mathrm{N}} \ldots \mathrm{O}$ is decreased from 3.30 to $2.72 \AA$, and the calculation qualitatively explains the experimental results. However, quantitative agreement was not obtained. This may be because, strictly speaking, the position of the amide proton in the $>\mathrm{N}-\mathrm{H} \cdots \mathrm{O}=\mathrm{C}<$ hydrogen bond depends on $\mathrm{R}_{\mathrm{N}} \ldots \mathrm{O},{ }^{95}$ but in this calculation the $\mathrm{N}-\mathrm{H}$ bond length was fixed at $1.0 \AA$.

Shoji et al. ${ }^{108}$ have determined the hydrogen-bonded amide $\mathrm{N}-\mathrm{H}$ bond lengths of poly(L-alanine)s with the $\alpha$-helix and $\beta$-sheet forms by analyzing the ${ }^{1} \mathrm{H}$ CRAMPS NMR spectra of fully ${ }^{15} \mathrm{~N}$-labeled poly(L-alanine)s in the solid state. The $\mathrm{N}-\mathrm{H}$ dipolar spinning sideband pattern of $\alpha$-helical poly(L-alanine) is different from that of $\beta$-sheet poly(L-alanine). The sideband pattern is characteristic of the $\mathrm{N}-\mathrm{H}$ bond length. From the sideband pattern analysis, the $\mathrm{N}-\mathrm{H}$ bond lengths for the $\alpha$-helix and $\beta$-sheet forms of poly(L-alanine) were determined to be 1.09 and $1.12 \AA$, respectively. It was shown that the $\mathrm{N}-\mathrm{H}$ bond length of the former is shorter than that of the latter.

Finally, the author would like to note that this review was given as an oral presentation at the Commemorative 30th Anniversary Meeting of the NMR Research Group of the Society of Polymer Science, Tokyo, Japan, December 8 and 9, 2011.

\section{ACKNOWLEDGEMENTS}

I thank my colleagues at the Tokyo Institute of Technology, who have greatly contributed to the current research program. Some of these studies were coauthored by Professor Hajime Saitô of the Himeji Institute of Technology, Professor Akira Shoji of Gunma University and Professor Tetsuo Asakura of Tokyo University of Agriculture and Technology, and I greatly acknowledge them and their colleagues.

1 Gutowsky, H. S., Saika, A., Takeda, M. \& Woessner, D. E. Proton magnetic resonance studies on natural rubber. II. Line shape and $T_{1}$ measurements. J. Chem. Phys. 27, 534 (1957).

2 Meyer, L. H., Saika, A. \& Gutowsky, H. S. Electron distribution in molecules. III. The proton magnetic spectra of simple organic groups. J. Am. Chem. Soc. 75, 4567 (1953).

3 Bovey, F. A. \& Tiers, G. V. D. Polymer NSR spectroscopy. II. The high resolution spectra of methyl methacrylate polymers prepared with free radical and anionic initiators. J. Polym. Sci. 44, 173 (1960).

4 Nishioka, A., Watanabe, H., Yamaguchi, I. \& Shimizu, H. High resolution NMR spectra of isotactic and syndiotactic polymethyl methacrylate in chloroform solution. J. Polym. Sci. 45, 232 (1960).
5 Johnsen, U. \& Tessmar, K. Wissenschaftliche Kurzberichte Hochaufgelöste Kernresonanzspektren von eutaktischen Polymethylmethacrylaten. Kolloid-Z. 168, 160 (1960)

6 Ando, I. \& Webb, G. A. Theory of NMR Parameters (Academic Press, London, 1983). 7 Ando, I. \& Asakura, T. Chemical shift calculations and stereochemical structures of synthetic polymers. Ann. Repts. NMR Spectrosc. 10A, 81, 1980).

8 Ando, I. \& Asakura, T. (ed.) Solid State NMR of Polymers (Elsevier Science, Amsterdam, 1998).

9 Ramsey, N. F. Magnetic shielding of nuclei in molecules. Phys. Rev. 78, 699 (1950)

10 Ramsey, N. F. Chemical effects in nuclear magnetic resonance and in diamagnetic susceptibility. Phys. Rev. 86, 243 (1952).

11 Saika, A. \& Slichter, C.P.A. Note on the fluorine resonance shifts. J. Chem. Phys. 22, 26 (1954).

12 Pople, J. A. The theory of chemical shifts in nuclear magnetic resonance. I. Induced current densities. Proc. R. Soc. London A239, 541 (1957).

13 Pople, J. A. The theory of chemical shifts in nuclear magnetic resonance. II. Interpretation of proton shifts. Proc. R. Soc. London A239, 550 (1957).

14 Ando, I., Nishioka, A. \& Asakura, T. The proton chemical shifts and the stereochemical structures of poly(vinyl chloride). Makromol. Chem. 176, 411 (1975)

15 Ando, I., Kato, Y. \& Nishioka, A. ${ }^{13} \mathrm{C}$ NMR chemical shifts and stereochemical structures in poly(vinyl chloride). Makromol. Chem. 177, 2759 (1976).

16 Ando, I., Kato, Y., Kondo, M. \& Nishioka, A. Solvent effect on the ${ }^{13} \mathrm{C}$ NMR chemical shifts of meso and racemic 2,4-dichloropentanes as the model compounds of poly(vinyl chloride). Makromol. Chem. 178, 803 (1977).

17 Andre, J. M. \& Ladik, J. Electronic Structure of Polymer and Molecular Crystals (Plenum Press, New York, 1974).

18 Andre, J. M., Delhalle, J. \& Ladik, J. Quantum Theory of Polymers (Reidel, Dordrecht, 1978).

19 Ladik, J. Quantum Theory of Polymers as Solids (Plenum Press, New York, 1988)

20 Sone, M., Yoshimizu, H., Kurosu, H. \& Ando, I. Side-chain conformation of poly(Lproline) form II in the crystalline state as studied by high-resolution solid-state ${ }^{13} \mathrm{C}$ NMR spectroscopy. J. Mol. Structure 317, 111 (1994).

21 Kurosu, H., Kikuchi, M. \& Ando, I. Structural characterization of polypyrrole in the solid state by high resolution ${ }^{15} \mathrm{~N}$ NMR spectroscopy [II]. J. Polym. Sci. Polym. Phys 33, 769 (1995).

22 Yamanobe, T., Chujo, R. \& Ando, I. Carbon-13 N.M.R. chemical shift and electronic structure of an infinite polymer chain as studied by tight-binding MO theory Polyethylene, and cis and trans polyacetylenes. Mol. Phys. 50, 1231 (1983).

23 Yamanobe, T. \& Ando, I. ${ }^{13} \mathrm{C}$ NMR chemical shift and electronic structure of an infinite polymer chain as studied by tight-binding theory within the CNDO/2 framework: Polyethylene and cis and trans polyacetylenes. J. Chem. Phys. 83, 3154 (1985).

24 Yamanobe, T., Ando, I., Saitô, H., Tabeta, R., Shoji, A. \& Ozaki, T. Carbon-13 NMR chemical shift and electronic structure of solid polypeptides as studied by tightbinding MO theory. polyglycine and poly(L-alanine). Bull. Chem. Soc. Japan 58, 23 (1985)

25 Yamanobe, T., Ando, I., Saitô, H., Tabeta, R., Shoji, A. \& Ozaki, T. Carbon-13 NMR chemical shift and electronic structure of polypeptide as studied by tight-binding MO theory: poly( $\beta$-benzyl L-aspartate) with the right-handle $\alpha$-helix and left-handed $\alpha$-helix forms. Chem. Phys. 99, 259 (1985).

26 Yamanobe, T., Sorita, T., Komoto, T. \& Ando, I. ${ }^{13} \mathrm{C}$ NMR chemical shift and crystal structure of paraffins and polyethylene as studied by solid state NMR. J. Mol. Structure 131, 267 (1985).

27 Yamanobe, T., Ando, I. \& Webb, G. A. ${ }^{13} \mathrm{C}$ NMR Chemical shifts and electronic structure of cis and trans polycetylenes as studied by tight-binding theory within the INDO/S framework. J. Mol. Structure, Theochem. 151, 191 (1987).

28 Kurosu, H., Yamanobe, T. \& Ando, I. Interchain effect of ${ }^{13} \mathrm{C}$ nuclear magnetic resonance chemical shift and electronic structure of polyoxymethylene chains in the solid state. J. Chem. Phys. 89, 5216 (1988).

29 Ishii, T., Kurosu, H., Yamanobe, T. \& Ando, I. Effect of interchain interactions on ${ }^{13} \mathrm{C}$ nuclear magnetic resonance chemical shifts and electronic structures of polyacetylene in the solid state as studied by tight-binding molecular orbital theory. J. Chem. Phys. 89, 7315 (1988).

30 Kurosu, H., Ando, I. \& Yamanobe, T. ${ }^{13} \mathrm{C}$ NMR Chemical shift and crystal structure of polyethylene chains in the solid state as studied by tight-binding theory within the INDO/S framework. J. Mol. Structure, Theochem. 201, 239 (1989).

31 Ando, I., Yamanobe, T. \& Kurosu, H. N.M.R. Nuclear shielding and the electronic structures of macromolecules. Ann. Rep. NMR Spectrosc. 22, 205 (1990).

32 Uchida, M., Toida, Y., Kurosu, H. \& Ando, I. An MO study on ${ }^{13} \mathrm{C}$ NMR chemical shift and the electronic structure of a three-dimensional polymer crystal by ab initio tightbinding MO theory: I. Polyethylene crystal. J. Mol. Structure 508, 181 (1999).

33 Fujii, K., Kuroki, S., Uchida, M., Kurosu, H. \& Ando, I. ${ }^{13} \mathrm{C}$ NMR chemical shift and electronic structure of a three-dimensional polyacetylene crystal by ab initio tight binding MO theory. J. Mol. Structure 602/603, 3 (2002).

34 Saitô, H., Tabeta, R., Shoji, A., Ozaki, T. \& Ando, I. Conformational characterization of polypeptides in the solid state as viewed from the conformation-dependent carbon-13 chemical shifts determined by the carbon- 13 cross polarization/magic angle spinning method: oligo(L-alanine), poly(L-alanine), copolymers of $\mathrm{L}$ - and $\mathrm{D}$-alanines, and copolymers of L-alanine with $\mathrm{N}$-methyl- or $\mathrm{N}$-benzyl-L-alanine. Macromolecules $\mathbf{1 6}$, 1050 (1983) 
35 Saitô, H., Tabeta, R., Shoji, A., Ozaki, T., Ando, I. \& Asakura, T. in Magnetic Resonance in Biology and Medicine. Govil, G., Khetrapal, C.L. \& Saran, A. (eds). (Tata McGraw-Hill, New Dehli, 1985).

36 Saitô, H. \& Ando, I. High-resolution solid-state NMR studies of synthetic and biological macromolecules. Ann. Rep. NMR Spectrosc. 21, 209 (1989)

37 Ando, I., Yamanobe, T. \& Asakura, T. Primary and secondary structures of synthetic polymer systems as studied by ${ }^{13} \mathrm{C}$ NMR spectroscopy. Prog. NMR Spectrosc. 22, 349 (1990).

38 Saitô, H. Conformation-dependent ${ }^{13} \mathrm{C}$ chemical shifts: a new means of conformational characterization as obtained by high-resolution solid-state ${ }^{13} \mathrm{C}$ NMR. Magn. Reson. Chem. 24, 835 (1986).

39 Ando, S., Yamanobe, T., Ando, I., Shoji, A., Ozaki, T. \& Saitô, H. Conformational characterization of glycine residues incorporated into some homopolypeptides by solid-state carbon-13 NMR spectroscopy. J. Am. Chem. Soc. 107, 7648 (1985).

40 Saitô, H., Ando, I. \& Ramamoorthy, A. Chemical shift tensor - the heart of NMR insights into biological aspects of proteins. Prog. NMR Spectrosc. 57, 181 (2010).

41 Saitô, H., Tabeta, R., Ando, I., Ozaki, T. \& Shoji, A. A high resolution ${ }^{13} \mathrm{C}$ NMR study of solid poly( $\beta$-benzyl-L-aspartate) by the cross polarization-magic angle spinning method distinction of the right-handed $\alpha$-helix, left-handed $\alpha$-helix, $\omega$-helix, and $\beta$ sheet forms by conformation-dependent ${ }^{13} \mathrm{C}$ chemical shifts. Chem. Letts. 1437 (1983).

42 Saitô, H., Tabeta, R., Shoji, A., Ozaki, T., Ando, I. \& Miyata, T. A high-resolution 13C nmr study of collagenlike polypeptides and collagen fibrils in solid state studied by the cross-polarization-magic angle-spinning method. Manifestation of conformationdependent ${ }^{13} \mathrm{C}$ chemical shifts and application to conformational characterization. Biopolymers 23, 2279 (1984).

43 Yoshimizu, $\mathrm{H}$. \& Ando, I. Conformational characterization of wool keratin and S-(carboxymethyl)kerateine in the solid state by carbon-13 CP/MAS NMR spectroscopy. Macromolecules 23, 2908 (1990).

44 Yoshimizu, H., Mimura, H. \& Ando, I. Carbon-13 CP/MAS NMR study of the conformation of stretched or heated low-sulfur keratin protein films. Macromolecules 24, 862 (1991).

45 Saitô, H., Tabeta, R., Asakura, T., Iwanaga, Y., Shoji, A., Ozaki, T. \& Ando, I. High resolution carbon-13 NMR study of silk fibroin in the solid state by the cross polarization-magic angle spinning method. Conformational characterization of silk and silk II type forms of Bombyx mori fibroin by the conformation-dependent carbon13 chemical shifts. Macromolecules 17, 1405 (1984).

46 Yamanobe, T., Tsukahara, M., Komoto, T., Watanabe, J., Ando, I., Uematsu, I., Deguchi, K., Fujito, T. \& Imanari, M. Conformation and dynamic aspects of poly $(\gamma-n-$ octadecyl L-glutamate) in the solid state and liquid-crystalline state as studied by variable-temperature carbon-13 CP/MAS NMR spectroscopy. Macromolecules 21 , 48, (1988).

47 Ando, I. \& Yamanobe, T. in Thermotropic Liquid Crystals: Recent Advance. Ramamoorthy, A. (ed.) Chapter 7, p. 176, (Springer, 2007).

48 Zhao, C., Zhang, H., Yamanobe, T., Kuroki, S. \& Ando, I. Diffusional behavior of solvent in polypeptide liquid crystalline and gel states with highly oriented chains as studied by NMR spectroscopy. Macromolecules 32, 3389( (1999).

49 Yin, Y., Zhao, C., Kuroki, S. \& Ando, I. Diffusional behavior of polypeptides in the thermotropic liquid crystalline state as studied by the pulse field-gradient spin-echo ${ }^{1} \mathrm{H}$ nuclear magnetic resonance method. J. Chem. Phys. 113, 7635 (2000).

50 Murata, K., Kuroki, S. \& Ando, I. A study of the conformational stability of poly(Lalanine), poly(D-alanine), poly(L-isoleucine), polyglycine and poly(L-valine) and their polypeptide blends in the solid-state by ${ }^{13} \mathrm{C}$ CP/MAS NMR. Polymer. 43, 6871 (2002).

51 Murata, K., Kono, H., Katoh, E., Kuroki, S. \& Ando, I. A study of conformational stability of polypeptide blends by solid state two-dimensional ${ }^{13} \mathrm{C}-{ }^{1} \mathrm{H}$ heteronuclear correlation NMR spectroscopy. Polymer 44, 4021 (2003).

52 Saitô, H., Ando, I. \& Naito, A. Solid State NMR Spectroscopy for Biopolymers (Kluwer Academic Press, London, 2006).

53 Akieda, T., Mimura, H., Kuroki, S., Kurosu, H. \& Ando, I. Conformational behavior of poly( $\beta$-benzyl L-aspartate) in the solid state as studied by variable-temperature carbon-13 cross-polarization/magic angle spinning nuclear magnetic resonance spectroscopy. Macromolecules 25, 5794 (1992).

54 Okabe, M., Yamanobe, T., Komoto, T., Watanabe, J., Ando, I. \& Uematsu, I. Conformational behaviour of poly ( $\beta$-aspartate) with $n$-alkyl side chains in the solid state as studied by ${ }^{13} \mathrm{C}$-CP/MAS-NMR spectroscopy. J. Mol. Structure 213, 213 (1989).

55 Ando, I. Helix change of polypeptides in the solid state as studied by NMR spectroscopy. Macromol. Symp. 101, 371 (1996).

56 Shoji, A., Ozaki, T., Fujito, T., Deguchi, K. \& Ando, I. High-resolution nitrogen-15 NMR study of solid homopolypeptides by the cross-polarization-magic angle spinning method: conformation-dependent nitrogen-15 chemical shifts characteristic of the $\alpha$ helix and $\beta$-sheet forms. Macromolecules 20, 2441 (1987).

57 Shoji, A., Ozaki, T., Fujito, T., Deguchi, K., Ando, S. \& Ando, I. Nitrogen-15 NMR chemical shift tensors and conformation of some nitrogen-15-labeled polypeptides in the solid state. Macromolecules 22, 2860 (1989).

58 Shoji, A., Ozaki, T., Fujito, T., Deguchi, K., Ando, S. \& Ando, I. Nitrogen-15 chemical shift tensors and conformation of solid polypeptides containing ${ }^{15} \mathrm{~N}$-labeled L-alanine residue by ${ }^{15}$ N NMR. 2. Secondary structure is reflected in $\sigma_{22}$. J. Am. Chem. Soc. 112, 4693 (1990)

59 Shoji, A., Ando, S., Kuroki, S., Ando, I. \& Webb, G.A. Structural studies of peptides and polypeptides in the solid state by nitrogen-15 NMR. Ann. Rep. NMR Spectrosc. 26, 55 (1993).
60 Kuroki, S., Ando, I., Shoji, A. \& Ozaki, T. A structural study of polyglycine II in the solid state by ${ }^{17}$ O CPMAS NMR spectroscopy. J. Chem. Soc., Chem. Commun. 433 (1992).

61 Kuroki, S., Takahashi, A., Ando, I., Shoji, A. \& Ozaki, T. Hydrogen-bonding structural study of solid peptides and polypeptides containing a glycine residue by ${ }^{17} \mathrm{O}$ NMR spectroscopy. J. Mol. Structure 323, 197 (1994).

62 Kuroki, S., Yamauchi, K., Ando, I., Shoji, A. \& Ozaki, T. ${ }^{17}$ O-isotope labeling and hydrogen-bonded structure investigation in peptides and polypeptides by solid state ${ }^{17}$ O NMR. Curr. Org. Chem. 5, 1001 (2001).

63 Takahashi, A., Kuroki, S., Ando, I., Ozaki, T. \& Shoji, A. Hydrogen-bonded structure and NMR parameters of oxygen-17 labeled poly(L-alanine)s as studied by solid state oxygen-17 NMR spectroscopy. J. Mol. Structure 442, 195 (1998).

64 Yamauchi, K., Kuroki, S., Ando, I., Ozaki, T. \& Shoji, A. ${ }^{17}$ O NMR chemical shifts and quadrupole coupling constants in solid poly(L-alanine)s determined using a highspeed MAS technique. Chem. Phys. Letts. 302, 331 (1999).

65 Yamauchi, K., Kuroki, S. \& Ando, I. High-resolution solid-state ${ }^{17} \mathrm{O}$ NMR studies of polyglycines and their hydrogen-bonded structures. J. Mol. Structure 602/603, 171 (2002).

66 Kuroki, S., Ando, S. \& Ando, I. An MO study of nuclear quadrupolar coupling constant and nuclear shielding of the carbonyl oxygen in solid peptides with hydrogen bonds. Chem. Phys. 195, 107 (1995).

67 Crich, F. H. C. \& Rich, A. Structure of polyglycine II. Nature 176, 780 (1955)

68 Amott, S. \& Wonacott, A.L. Atomic co-ordinates for an $\alpha$-helix: refinement of the crystal structure of $\alpha$-poly-L-alanine. J. Mol. Biol. 21, 371 (1966).

69 Amott, S., Dover, S. D. \& Elliot, A. Structure of $\beta$-poly-L-alanine: refined atomic coordinates for an anti-parallel beta-pleated sheet. J. Mol. Biol. 30, 201 (1967).

70 Lemaitre, V., de Planque, M. R. R., Howes, A. P., Smith, M. E., Dupree, R. \& Watts, A. Solid-state ${ }^{17} \mathrm{O}$ NMR as a probe for structural studies of proteins in biomembranes. J. Am. Chem. Soc. 126, 15321 (2004).

71 Shoji, A., Kimura, H., Ozaki, T., Sugisawa, H. \& Deguchi, K. Conformational study of solid polypeptides by $1 \mathrm{H}$ combined rotation and multiple pulse spectroscopy NMR. J. Am. Chem. Soc. 118, 7604 (1996).

72 Shoji, A., Kimura, H. \& Sugisawa, H. Structural studies of amino acids, polypeptides and proteins in the solid state by ${ }^{1} \mathrm{H}$ CRAMPS NMR. Ann. Rep. NMR Spectrosc. 45, 69 (2002).

73 Yamauchi, K., Kuroki, S., Fujii, K. \& Ando, I. The amide proton NMR chemical shift and hydrogen-bonded structure of peptides and polypeptides in the solid state as studied by high-frequency solid-state ${ }^{1}$ H NMR. Chem. Phys. Letts. 324, 435 (2000).

74 Yamauchi, K., Kuroki, S. \& Ando, I. The amide proton NMR chemical shift and hydrogen-bonded structure of glycine-containing peptides and polypeptides in the solid state as studied by multi-pulse-associated high-speed MAS ${ }^{1} \mathrm{H}$ NMR. J. Mol. Structure 602/603, 9 (2002)

75 Yamauchi, K., Kuroki, S. \& Ando, I. Structural characterization of nylon 4 in the solid state by high-resolution solid-state ${ }^{1}$ H NMR spectroscopy. Polymer 43, 3331 (2002).

76 Ando, I., Saitô, H., Tabeta, R., Shoji, A. \& Ozaki, T. Conformation-dependent carbon13 NMR chemical shifts of poly(L-alanine) in the solid state: FPT INDO calculation of $\mathrm{N}$-acetyl- $\mathrm{N}^{\prime}$-methyl-L-alanine amide as a model compound of poly(L-alanine) Macromolecules 17, 457 (1984).

77 Asakawa, N., Kurosu, H. \& Ando, I. Structural study of peptides containing L-alanine residues by ab initio chemical shielding calculation. J. Mol. Structure 323, 279 (1994).

78 Asakawa, N., Kurosu, H., Ando, I., Shoji, A. \& Ozaki, T. A structural study of peptides and proteins containing L-alanine residues by ${ }^{13} \mathrm{C}$ NMR spectroscopy combined with ab initio chemical shift calculations. J. Mol. Structure 317, 119 (1994).

79 Naito, A., Ganapathy, S., Akasaka, K. \& McDowell, C. A. Chemical shielding tensor and ${ }^{13} \mathrm{C}-{ }^{14} \mathrm{~N}$ dipolar splitting in single crystals of L-alanine. J. Chem. Phys. 74, 3190 (1981).

80 de Dios, A. C., Pearson, J. G. \& Oldfield, E. Secondary and tertiary structural effects on protein NMR chemical shifts: an ab initio approach. Science 260, 1491 (1993).

81 Spera, S. \& Bax, A. Empirical correlation between protein backbone conformation and $\mathrm{C}_{\alpha}$ and $\mathrm{C}_{\beta}{ }^{13} \mathrm{C}$ nuclear magnetic resonance chemical shifts. J. Am. Chem. Soc. 113, 5490 (1991).

82 Asakura, T., Iwadate, M., Demura, M. \& Williamson, M. P. Structural analysis of silk with ${ }^{13} \mathrm{C}$ NMR chemical shift contour plots. Int. J. Biol. Macromol. 24, 167 (1999).

83 Iwadate, M., Asakura, T. \& Williamson, M. P. $C_{\alpha}$ and $C_{\beta}$ carbon- 13 chemical shifts in proteins from an empirical database. J. Biomol. NMR 13, 199 (1999).

84 Jeffrey, G.A. An Introduction to Hydrogen Bonding (Oxford University Press, New York, 1997).

85 Asakawa, N., Kameda, T., Kuroki, S., Kurosu, H., Ando, S., Ando, I. \& Shoji, A. Structural studies of hydrogen-bonded peptides and polypeptides by solid-state NMR Ann. Rep. NMR Spectrosc. 35, 55 (1998).

86 Ando, I., Kuroki, S., Kurosu, H., Uchida, M. \& Yamanobe, T. Modeling NMR chemical shifts in polymers and amorphous matter. ACS Symp. Ser. 732, 24 (1999).

87 Ando, I., Kuroki, S., Kurosu, H. \& Yamanobe, T. NMR chemical shift calculations and structural characterizations of polymers. Prog. NMR Spectrosc. 39, 79 (2001)

88 Ando, S., Ando, I., Shoji, A. \& Ozaki, T. Intermolecular hydrogen-bonding effect on carbon-13 NMR chemical shifts of glycine residue carbonyl carbons of peptides in the solid state. J. Am. Chem. Soc. 110, 3380 (1988).

89 Asakawa, N., Kuroki, S., Kurosu, H., Ando, I., Shoji, A. \& Ozaki, T. Hydrogen-bonding effect on carbon-13 NMR chemical shifts of L-alanine residue carbonyl carbons of peptides in the solid state. J. Am. Chem. Soc. 114, 3261 (1992).

90 Tsuchiya, K., Takahashi, A., Takeda, N., Asakawa, N., Kuroki, S., Ando, I., Shoji, A. \& Ozaki, T. Hydrogen-bonding effect on ${ }^{13} \mathrm{C}$ NMR chemical shifts of amino acid residue carbonyl carbons of some peptides in the crystalline state. J. Mol. Structure 350, 233 (1995). 
91 Ando, I., Kameda, T., Asakawa, N., Kuroki, S. \& Kurosu, H. Structure of peptides and polypeptides in the solid state as elucidated by NMR chemical shift. J. Mol. Structure 441, 213 (1998).

92 Takeda, N., Kuroki, S., Kurosu, H. \& Ando, I. ${ }^{13} \mathrm{C}-\mathrm{NMR}$ chemical shift tensor and hydrogen-bonded structure of glycine-containing peptides in a single crystal. Biopolymers 50, 61 (1999).

93 Hertzfeld, J. \& Berger, E. Sideband intensities in NMR spectra of samples spinning at the magic angle. J. Chem. Phys. 73, 6021 (1980).

$94 \mathrm{Gu}$, Z. \& McDermott, A. E. Chemical shielding anisotropy of protonated and deprotonated carboxylates in amino acids. J. Am. Chem. Soc. 115, 4282 (1993).

95 Kameda, T., Takeda, N., Kuroki, S., Ando, S., Ando, I., Shoji, A. \& Ozaki, T. Hydrogenbonded structure and ${ }^{13} \mathrm{C}$ NMR chemical shift tensor of amino acid residue carbonyl carbons of peptides and polypeptides in the crystalline state. Part I. J. Mol. Structure 384, 17 (1996).

96 Kuroki, S., Ando, S., Ando, I., Shoji, A., Ozaki, T. \& Webb, G. A. Hydrogen-bonding effect on ${ }^{15} \mathrm{~N}$ NMR chemical shifts of the glycine residue of oligopeptides in the solid state as studied by high-resolution solid-state NMR spectroscopy. J. Mol. Structure 240, 19 (1990).

97 Kuroki, S., Asakawa, N., Ando, S., Ando, I., Shoji, A. \& Ozaki, T. Hydrogen bond length and ${ }^{15} \mathrm{~N}$ NMR chemical shift of the glycine residue of some oligopeptides in the solid state. J. Mol. Structure 245, 69 (1991).

98 Hiyama, Y., Niu, C. H., Silverton, J. V., Bavoso, A. \& Torcha, D. A. Determination of $15 \mathrm{~N}$ chemical shift tensor via ${ }^{15} \mathrm{~N}-{ }^{2} \mathrm{H}$ dipolar coupling in Boc-glycylglycyl[15N glycine]benzyl ester. J. Am. Chem. Soc. 110, 2378 (1988).
99 Kuroki, S., Yamauchi, K., Kurosu, H., Ando, S., Ando, I., Shoji, A. \& Ozaki, T. ${ }^{17} \mathrm{O}$ NMR Chemical Shifts in Peptides. ACS Symp. Ser. 732, 126 (1999).

100 Astbury, W. T., Dalgleish, C. H., Darmon, S. E. \& Sutherland, G. B. B. M. Studies of the structure of synthetic polypeptides. Nature 69, 596 (1948).

101 McDermott, A. E. \& Ridenour, C. F. in Encyclopedia of NMR. Grant, D. M. \& Harris, R. K. (eds). (John Wiley \& Sons, New York, 1996).

102 Wei, Y. \& McDermott, A. E. Effects of hydrogen bonding on ${ }^{1} \mathrm{H}$ chemical shifts. ACS Symp. Ser. 732, 177 (1999).

103 Bielecki, A., Kolbert, A. C. \& Levitt, M. H. Frequency-switched pulse sequences: homonuclear decoupling and dilute spin NMR in solids. Chem. Phys. Letts 155, 341 (1989).

104 Levitt, M. H., Kolbert, A. C., Bielecki, A. \& Ruben, D. J. High-resolution ${ }^{1}$ H NMR in solids with frequency-switched multiple-pulse sequences. Solid State NMR 2, 151 (1993).

105 Hafner, S. \& Spiess, H. W. Multiple-pulse line narrowing under fast magic-angle spinning. J. Magn. Reson. A 121, 160 (1996)

106 Hafner, S. \& Spiess, H. W. Multiple-pulse assisted line-narrowing by fast magic-angle spinning. Solid State NMR 8, 17 (1997).

107 Hori, S., Yamauchi, K., Kuroki, S. \& Ando, I. Proton NMR chemical shift behavior of hydrogen-bonded amide proton of glycine-containing peptides and polypeptides as studied by ab initio MO calculation. Int. J. Mol. Sci. 3, 907 (2002).

108 Kimura, H., Shoji, A., Sugisawa, H., Deguchi, K., Naito, A. \& Saitô, H. Determination of $\mathrm{N}-\mathrm{H}$ bond lengths of ${ }^{15} \mathrm{~N}$-labeled poly(l-alanines) by ${ }^{1} \mathrm{H}$ CRAMPS NMR. Macromolecules 33, 6627 (2000).

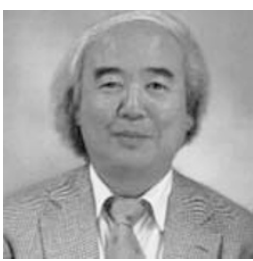

Professor Isao Ando was born in Tokyo, Japan in 1941. He received his BS degree in 1966 from Tokyo University of Science, his Master degree in 1969 and his Doctoral degree of Engineering in 1972 from Tokyo Institute of Technology (TITECH) under the supervision of late Professor Atsuo Nishioka. After receiving his Dr degree, he was employed as a Research Associate of TITECH at once. He became an Associate Professor in 1983 and a Professor of TITECH in 1988. Since 2001, he became a Director of International Research Center of Macromolecular Science in TITECH as an additional post. He retired from TITECH in 2005 (Professor Emeritus of TITECH). His scientific interests were elucidation and characterization of structure and dynamics of polymers or biopolymers using various NMR techniques and development of the $a b$ initio chemical shift calculation. He was a recipient of The Award of the Society of Polymer Science, Japan in 1991 and The Award for Outstanding Achievement in Polymer Science and Technology for his contribution of Development of Polymer NMR Spectroscopy and Its Application for Structural and Dynamic Characterization of Polymers from the Society of Polymer Science, Japan in 2002. Furthermore, he was a president of The Nuclear Magnetic Resonance Society of Japan during 2006-2007 and had been commended to be an Honorary member of The Nuclear Magnetic Resonance Society of Japan in 2011. He is a fellow of International Society for Magnetic Resonance and of IUPAC. In addition, he has consecutively occupied a number of positons as Editor and in Editorial Advisory Boards in many Journals, such as Polymer Journal, Macromolecules, Journal of Molecular Structure, Polymer Bulletin, Magnetic Resonance in Chemistry, Encyclopedia of NMR and so on. He is the author and coauthor of ca. 400 original papers, reviews, books and patents. 